\title{
Union Wage Bargaining and the Incentive to Innovate*
}

\author{
Jörg Lingens ${ }^{\dagger}$
}

22nd March 2006

\begin{abstract}
We analyse the impact of union wage bargaining on the firm's incentive to invest into research. In a heterogenous Cournot duopoly, each firm invests resources into a patent race similar to Reinganum (1983) and bargains the wage with a labour union. Union wage bargaining affects the incentive to innovate through its effect on the profit situation of the firm. Besides the hold-up and the strategic effect which have been analysed in the literature, we are able to identify a third effect of union wage bargaining: its impact on the Arrow effect. This effect is positive for the research incentive. Solving the model numerically reveals that in sum, union wage bargaining decreases the incentive for doing research. This result is independent of the bargaining institution (right-to-manage or efficient bargaining) or the degree of product heterogeneity.

JEL: J51, O31, L51.

Keywords: Union Wage Bargaining, Arrow effect, Right-to-manage, Efficient Bargaining
\end{abstract}

*For helpful comments I would like to thank Lutz Arnold, Jörg Heining, Ralf Müller, Frank Neumann and participants at the Lunch Seminar of the University of Regensburg. All errors are, of course, mine

†University of Regensburg, Joerg.Lingens@wiwi.uni-regensburg.de, Tel.: ++49941943 2722 


\section{Introduction}

What is the impact of union wage bargaining on the firm's incentive to invest into R\&D? Obviously this question is important when we want to understand and judge the overall impact of unionisation on the "state" of the economy. However, the answer to this question naturally differs depending on whether you ask a labour union or a firm.

Labour unions will put forward that wage bargaining increases the incentive for the firm to invest into research. High wages increase the revenue of introducing a labour saving technology and thus spur R\&D. ${ }^{1}$

On the contrary, firms argue that the wage increase decreases the profit from an innovation. Consequently the incentive for performing R\&D declines and as such, research investment.

Which of these arguments is the correct or at least the dominating one? In a Continental European context this is important to know. Many EU15 economies reform and restructure their labour relations towards the anglosaxion model of more market coordination. Is this a means to enhance the research situation or will it make things even worse (compared for example to the US)?

Plotting aggregate R\&D expenditures (in \% of GDP) and union wage coverage for a set of EU15 countries and the US and Japan yields figure 1 which depicts a (insignificant) negative relationship between research investment and union wage bargaining. ${ }^{2}$ A good part of this effect is driven by the situation in Japan and the US with large R\&D expenditures and low degree of unionisation. The impact of unionisation on research investment within the EU15 is far from being clear (see the right panel in figure 1). The ambiguity of the union effect is also confirmed in econometric studies, see for example the paper of Menezes-Fihlo and Van Reenen (2003) who present a broad survey of the empirical literature on the effect of unions and innovation. They conclude that empirically, there is no consensus among these studies in which way unions affect innovation.

The theoretical literature which analyses the relation between union wage

\footnotetext{
${ }^{1}$ Another argument which centres more on the aggregate effect of unions on innovation goes that high wage demands foster the process of structural change since low-productivity firms are pushed out of the market. This argument is especially popular among Scandinavian trade union leaders. For a formal analysis of this argument, see Agell and Lommerud (1993).

${ }^{2}$ All figures refer to the year 2000 .
} 

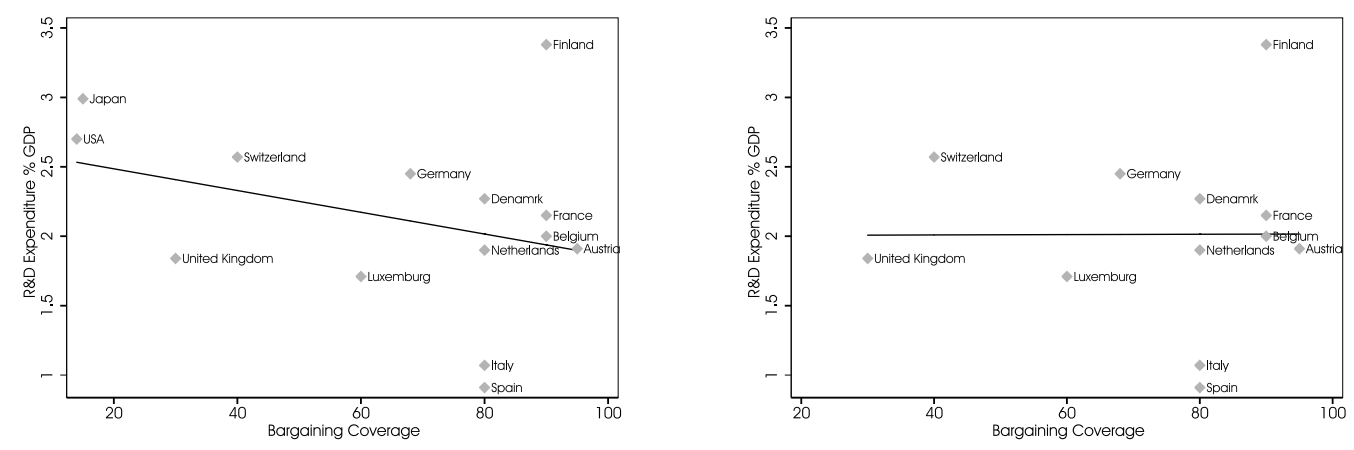

Figure 1: R\&D Expenditure and Union Coverage

bargaining and research investment is also far from being unambiguous. The early literature (see for example Grout (1984) or Ploeg (1987)) focussed very much on the hold-up effect of the union. The basic idea is that if research takes the form of some sunk investment, the union accrues part of the quasirent generated by this investment. The firm anticipates this hold-up in the first place and research investment declines.

More recently, however, the focus has moved away from the hold-up effect of union wage bargaining to its effect on the strategic incentive for doing R\&D, see for example Ulph and Ulph (1994), (1998), (2001), Menezes-Fhilo et al. (1998) or more recently Haucap and Wey (2004). Firms do not only have a direct incentive for investing into $R \& D$, i.e. the profit effect, but also because the innovative firm gains a strategic advantage over its competitors. Union wage bargaining strengthens this strategic incentive for doing research. The wage hike associated with wage bargaining makes the position of the non-innovating firm less attractive. This fosters investment into research.

The literature which takes the strategic effect into account, analyses the impact of union wage bargaining exclusively within a framework of a homogeneous Cournot duopoly. Within this framework the hold-up effect as well as the strategic effect are present (due to the oligopolistic competition). ${ }^{3}$ Which of the two effects dominates depends on the institutional setting of the wage bargain.

Ulph and Ulph (1994) show that in a right-to-manage setting the hold-

\footnotetext{
${ }^{3}$ The "wage differentiation hold-up" effect in the paper of Haucap and Wey (2004) is in some ways similar to the strategic effect.
} 
up effect dominates. This result, however, could be reversed with efficient bargaining, i.e. in a situation in which the bargain is over wages and employment.

Haucap and Wey (2004) focus on a right-to-manage setting, but consider different degrees of centralisation of the wage bargain. They argue that in general, unionisation decreases research investment of firms. The only exception to this, is the situation with centralised wage bargaining in which one union bargains a uniform wage for the two duopolists. In this case unionisation will foster the incentive to invest into research.

This literature forms the starting point of this paper. However, we extend this literature by two, in our view important, features. First, we consider the possibility of product heterogeneity which sheds some light on how the strategic incentive is affected by a different goods market structure. Second, we take a different stand on modelling the process of research investment.

Ulph and Ulph (1994) model the research investment as a sealed bid auction. Haucap and Wey (2004) consider a very simple tournament to determine which firm is able to implement the innovation. We think this modelling oversimplifies since it assumes that the incentive for research investment is only driven by a.) the profit when being the innovator and b.) the profit when the competitor is the innovator. ${ }^{4}$ However, we know from the industrial organisation literature that a more sophisticated modelling of the research process gives rise to an additional effect that is important for R\&D investment, see for example Tirole (1988) or Reinganum (1983). This effect is driven by the profit flow during a patent race as long as no firm has found the innovation yet and is usually referred to as the Arrow or the replacement effect. $^{5}$

The union and innovation literature has neglected this effect although it is important since it is an additional transmission channel through which wage bargaining influences research investment and hence innovation. The wage hike of the union decreases the profit flow during the patent race. This increases the firms' incentive to invest into innovation since they are eager to shorten the time until the innovation is found. The Arrow effect represents a second positive effect of union wage bargain on innovation which is the stronger, the more heterogeneous the products of the two duopolists are. As

\footnotetext{
${ }^{4}$ These two effects are the basis for the hold-up and the strategic effect of the union.

${ }^{5}$ Arrow was the first to analyse this effect in the context of a monopoly framework, see Tirole (1988).
} 
such, taking this effect into account could potentially reverse the negative impact of union wage bargaining on innovation which have been found in the literature, so far.

Numerical simulations of our model, however, show that even when taking the impact of the union wage bargaining on the Arrow effect into account, research investment will decline compared to a competitive labour market situation. This is true for a right-to-manage as well as for an efficient bargaining framework. Even introducing product heterogeneity does not modify this results.

Section 2 presents the framework for our analysis. In section 3 we derive the equilibrium conditions for both institutional wage bargaining set-ups (right-to-manage and efficient bargaining) and present a numerical solution for these equilibrium conditions. Finally, section 4 concludes.

\section{The Model}

\subsection{Consumer}

Following Dixit (1979) and Singh and Vives (1984) we consider an economy which produces three goods, $x_{1}, x_{2}$ and $x_{3}$. The good $x_{3}$ is assumed to be the numéraire good in the economy, i.e. its price is normalised to one. Moreover, we assume that this good is supplied by some competitive market which is taken to be exogenous. The other two goods $x_{1}$ and $x_{2}$ are supplied monopolistically.

Consumers are characterised by the following utility function:

$$
U\left(x_{1}, x_{2}, x_{3}\right)=\alpha\left(x_{1}+x_{2}\right)-\left(\left(x_{1}^{2}+x_{2}^{2}\right)+2 \gamma x_{1} x_{2}\right) / 2+x_{3},
$$

where utility is linear in the competitive good $x_{3}$. This ensures the shadow value of income to be one and thus, gives rise to the following linear (inverse) demand system for $x_{1}$ and $x_{2}$ (see, appendix A.1):

$$
\begin{aligned}
& p_{1}=\alpha-x_{1}-\gamma x_{2}, \\
& p_{2}=\alpha-x_{2}-\gamma x_{1} .
\end{aligned}
$$

The parameter $\gamma$ depicts the substitutability between $x_{1}$ and $x_{2}$. For $\gamma>(<)$ 0 the goods are substitutes (complements). In what follows, we will focus on the case of $\gamma>0$. 
The inverse demand system (in which prices are given as a function of quantities) can be solved for the direct demand system (quantities as functions of prices):

$$
\begin{aligned}
& x_{1}=a-\frac{1}{b} p_{1}+\frac{\gamma}{b} p_{2}, \\
& x_{2}=a-\frac{1}{b} p_{2}+\frac{\gamma}{b} p_{1},
\end{aligned}
$$

where we defined for notational convenience $a:=\frac{\alpha-\alpha \gamma}{b}$ and $b:=1-\gamma^{2}$. We assume parameters to be such that $a$ and $b$ are positive.

Note that due to the symmetry of the monopolistic goods $x_{1}$ and $x_{2}$ in the utility function, the inverse and direct demand functions are symmetric, too.

\section{$2.2 \quad$ Firms}

The two firms under consideration produce output using labour and take part in a productivity enhancing patent race. The production function of both firms is symmetric and given by:

$$
\begin{aligned}
& x_{1}=\beta_{1} l_{1}, \\
& x_{2}=\beta_{2} l_{2},
\end{aligned}
$$

where $\beta_{i}$ is the input coefficient in sector $i \in 1,2$ and $l_{i}$ is the amount of labour employed. Since we do not want to break up the symmetry in the argumentation, we assume $\beta_{1}=\beta_{2}$ which we normalise to unity. With this specification of the production functions, it is obvious that marginal costs in both firms are constant and equal to the wage rate $w_{i}$.

Besides production, firms also engage in a (one-shot) patent race. They invest resources in order to find a better production process which reduces the labour requirement per unit output by a factor $0<\Delta<1$. This resembles somewhat the notion of an innovation in Haucap and Wey (2004). However, we do not assume that implementation of the new process is costly (as they do), but assume that discovering the innovation is a resource consuming process.

We model the patent race following rather close for example Reinganum (1983) and Tirole (1988). However, we assume that time is discrete. The innovation process takes the following form. At the beginning of every period $t$, 
firm $i$ invests resources $r_{i}$ into the innovation process. With probability $h\left(r_{i}\right)$ the firm is successful and can instantaneously implement the productivity enhancing process. Note that $h^{\prime}\left(r_{i}\right)>0, h^{\prime \prime}\left(r_{i}\right)<0$ and $\lim _{r_{i} \rightarrow \infty} h\left(r_{i}\right)<1$. $^{6}$ Thus, the firm can never be sure that it discovers the innovation at some point in $t$. Note that we assume the probability process which drives discovery of the innovation to be memoryless. This means that the probability of finding the innovation in the next period is constant throughout time. This is a standard assumption in the literature.

Once the innovation is found, it will be protected by an infinitely lasting patent. As such, the patent race ends once a firm has discovered the innovation. However, we assume that the innovation is non-drastic, i.e. the looser of the patent race is not pushed out of the market. ${ }^{7}$

As long as no firm has won the patent race, the (operating) flow profit of firm $i$ is given by:

$$
\Pi_{i}=\left(p_{i}-w_{i}\right) x_{i}-r_{i}
$$

Since we consider strategic interaction within the oligopoly, $p_{i}$ and $x_{i}$ are functions of the behaviour of firm $j$. Thus, the flow profit of firm $i$ will not only be a function of $w_{i}$, but also a function of the marginal cost situation in the other firm. A short-cut way to write this is $\Pi_{i}\left(w_{i}, w_{j}, r_{i}\right)$.

If firm $i$ was the first to discover the new process, its marginal costs would decrease and ceteris paribus the profit rate would increase. After the innovation the marginal cost of firm $i$ is $\Delta w_{i}$. Thus, the flow profit reads in this case $\Pi_{i}\left(\Delta w_{i}, w_{j}\right)$. Remember that after the innovation is discovered, the race ends and firm $i$ gets an infinite stream of this flow. Thus, the present value of winning the race (in the moment of winning) is:

$$
\sum_{t=1}^{\infty}\left(\frac{1}{1+\rho}\right)^{t} \Pi_{i}\left(\Delta w_{i}, w_{j}\right)=\frac{\Pi_{i}\left(\Delta w_{i}, w_{j}\right)}{\rho},
$$

where $\rho$ is the rate of time preference. In the case that firm $i$ looses the race, its (present value of) profits will be:

$$
\sum_{t=1}^{\infty}\left(\frac{1}{1+\rho}\right)^{t} \Pi_{i}\left(w_{i}, \Delta w_{j}\right)=\frac{\Pi_{i}\left(w_{i}, \Delta w_{j}\right)}{\rho} .
$$

\footnotetext{
${ }^{6}$ Such a function would be for example $\left(1-\left(1+r_{i}\right)^{-\omega}\right)$.

${ }^{7}$ We derive the condition for this to hold in the appendix.
} 
As long as no firm has won the patent race yet, the firm has to choose how much R\&D effort to invest. This investment choice is driven by maximising the present value of profits at some point $t$. The present value of profits can be derived by using the Bellman principle. ${ }^{8}$

$$
P V_{i t}=\max _{r_{i}}\left\{\frac{1}{1+\rho}\left(\Pi\left(w_{i}, w_{j}, r_{i}\right)+E\left(P V_{i t+1}\right)\right)\right\}
$$

where $E($.$) is the expectation operator. The present value of profits in t$ is the discounted flow profit plus the expected present value in the next period. The latter is given by: ${ }^{9}$.

$$
\left(1-h\left(r_{i}\right)-h\left(r_{j}\right)\right) P V_{i t+1}+h\left(r_{i}\right) \Pi\left(\Delta w_{i}, w_{j}\right) \rho^{-1}+h\left(r_{j}\right) \Pi\left(w_{i}, \Delta w_{j}\right) \rho^{-1},
$$

which is the probability weighted stream of profits. Thanks to the assumption of the memoryless investment process there is no interconnection between periods, i.e. the problem does not change between $t$ and $t+1$. Thus, we can plug-in (2.12) into (2.11) and get after some algebraic manipulations (skipping time indices):

$$
P V_{i}=\max _{r_{i}}\left\{\frac{\Pi\left(w_{i}, w_{j}, r_{i}\right)+h\left(r_{i}\right) \Pi\left(\Delta w_{i}, w_{j}\right) \rho^{-1}+h\left(r_{j}\right) \Pi\left(w_{i}, \Delta w_{j}\right) \rho^{-1}}{\rho+h\left(r_{i}\right)+h\left(r_{j}\right)}\right\} .
$$

The present value of profits is the time invariant expected profit flow discounted by a factor which takes the risk of winning and loosing the race into account. When choosing the optimal amount of research investment, firm $i$ will maximise (2.13) taking its potential effects on later stages of the game into account.

\subsection{Unions}

We assume that the labour market is dominated by firm level unions. These bargain the wage (and employment) with the firm after the R\&D choice has been made (i.e. we focus on the situation of ex-post bargaining, see Ulph and Ulph (1998)).

\footnotetext{
${ }^{8} \mathrm{I}$ am grateful to Lutz Arnold for suggesting this form of presentation.

${ }^{9}$ We assume that firms cannot innovate simultaneously, i.e the probability that both firms find an innovation is zero.
} 
To keep our results comparable to the existing literature, we assume the firm-level union to be characterised by a Stone-Geary utility function:

$$
V_{i}=\left(w_{i}-\bar{w}\right)^{\theta} l_{i}^{1-\theta},
$$

where $\bar{w}$ is the wage in the competitive case which is determined by some (exogenous) outside option. As already said, this Stone-Geary specification is quite popular in the unionised oligopoly literature, see for example Lopez and Naylor (2004). This is due to the fact that it is a.) quite easy to handle and b.) that it is a flexible specification. However, we are well aware of the fact that this specification is hard to reconcile with a utilitarian specification of union behaviour, see Oswald (1985).

\section{$2.4 \quad$ Timing}

Before solving for the equilibrium in the economy some words are in order concerning the timing of events. At the first stage of every period, firm $i$ chooses the amount of resources to invest into the research process, $r_{i}$. This choice is time invariant due to the fact that the process driving the discovery of an innovation is memoryless. After having made the choice of how much to invest, the patent race begins and it is instantaneously revealed which firm has won. Once the patent race is over, the firm level union bargains the wage for one period, conditional on the innovative status of the firm. At the last stage eventually, firms produce and engage in competition. After this, the whole sequence starts anew. When the patent race ends, the only events left will be bargaining and production. The timing of events is visualised in figure 2. The determination of the equilibrium in the economy is dictated by this timing structure. We use backward induction to solve for the equilibrium. First, we determine the optimal output given the innovation status in the economy and given the wage and research investment. Secondly, we solve the bargaining problem again given the innovation situation and the research investment. Using this information we can determine the profit of a firm $i$ for all three possible situations which in turn enables us to solve for the equilibrium research investment strategy. 


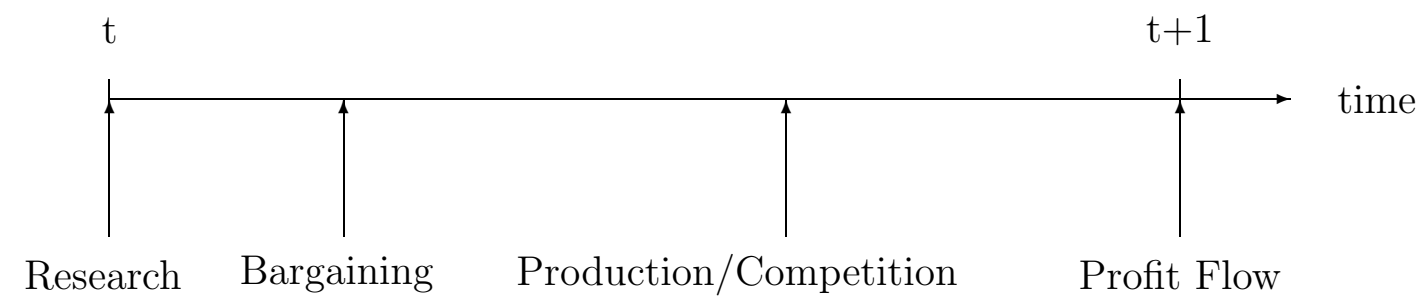

Figure 2: Timing of Events

\section{Equilibrium}

\subsection{Right-to-Manage}

\subsubsection{The Production Decision}

With Cournot competition every firm maximises the present value of its profit by choosing the amount of production that will be supplied to the market. The choice of firm $i$ how much to produce depends on the situation concerning the patent race. We can distinguish three different situations:

- none of the firms has found the innovation yet,

- firm $i$ has won the patent race and firm $j$ has lost it, or

- firm $j$ has won the patent race and firm $i$ has lost it.

Since the innovation status affects marginal costs, it will affect the strategic behaviour of every firm and thus will affect the amount of output which is produced in the economy.

3.1.1.1 No firm has found the innovation In the situation in which no firm has discovered the innovation, firm $i$ chooses output such as to maximise the following flow profit: ${ }^{10}$

$$
\Pi_{i}=\left(p_{i}-w_{i}\right) x_{i}-r_{i}
$$

\footnotetext{
${ }^{10}$ The choice of output has no intertemporal effects. Thus, in determining the optimal amount of production we can focus on the flow profit of one period. This would ceteris paribus maximise the present value of the profit stream.
} 
where the price $p_{i}$ is by equation (2.2) a function of the output choice. By profit maximisation the reaction curve for firm $i$ is:

$$
x_{i}=0.5\left(\alpha-\gamma x_{j}-w_{i}\right),
$$

which in turn gives the (Nash) equilibrium production of firm $i$ in case of no innovation:

$$
\begin{aligned}
x_{i} & =\frac{1}{4-\gamma^{2}}\left((2-\gamma) \alpha-2 w_{i}+\gamma w_{j}\right) \\
x_{j} & =\frac{1}{4-\gamma^{2}}\left((2-\gamma) \alpha-2 w_{j}+\gamma w_{i}\right) .
\end{aligned}
$$

The associated equilibrium profit is in this case:

$$
\Pi_{i}\left(w_{i}, w_{j}, r_{i}\right)=x_{i}\left(w_{i}, w_{j}\right)^{2}-r_{i}
$$

which is the standard result in the literature, see for example Singh and Vives (1984). As will become clear later, in the symmetric situation, wage demands from the unions will be identical. With this, output and profit will be identical as long as no firm has become the innovator.

3.1.1.2 Firm $i$ has won the patent race Turning to the second situation in which firm $i$ has won the patent race and can now produce with the enhanced technology. The flow profit function in this case reads:

$$
\Pi_{i}\left(\Delta w_{i}, w_{j}\right)=\left(p_{i}-\Delta w_{i}\right) x_{i}
$$

which results in the following reaction curve (see, appendix A.2.1):

$$
x_{i}=0.5\left(\alpha-\gamma x_{j}-\Delta w_{i}\right)
$$

Note that since firm $j$ lost the race, its reaction function reads:

$$
x_{j}=0.5\left(\alpha-\gamma x_{i}-w_{j}\right)
$$

The equilibrium amount of production is hence given by (see, appendix A.2.1):

$$
\begin{aligned}
& x_{i}=\frac{1}{4-\gamma^{2}}\left((2-\gamma) \alpha-2 \Delta w_{i}+\gamma w_{j}\right), \\
& x_{j}=\frac{1}{4-\gamma^{2}}\left((2-\gamma) \alpha-2 w_{j}+\Delta \gamma w_{i}\right) .
\end{aligned}
$$


The equilibrium profits for firm $i$ and $j$ are in turn given by:

$$
\begin{aligned}
& \Pi_{i}\left(\Delta w_{i}, w_{j}\right)=x_{i}\left(\Delta w_{i}, w_{j}\right)^{2}, \\
& \Pi_{j}\left(w_{j}, \Delta w_{i}\right)=x_{j}\left(w_{j}, \Delta w_{i}\right)^{2} .
\end{aligned}
$$

\subsubsection{Union Wage Bargaining}

Before production can take place, every firm has to bargain the wage with a union which represents all workers in the firm under consideration. The bargaining problem is solved using the Nash bargaining solution. The bargained wage will maximise: ${ }^{11}$

$$
\Omega=\delta \ln \left(V_{i}-\bar{V}_{i}\right)+(1-\delta) \ln \left(\Pi_{i}-\bar{\Pi}_{i}\right),
$$

where $\delta$ reflects the bargaining power of the union. $\bar{V}_{i}$ is the utility in case no agreement is settled. We assume this utility to be zero, because with no agreement employment is zero. $\bar{\Pi}_{i}$ is the profit of firm $i$ in case of no agreement. This depends on the innovation status in the economy. As long as no innovation has been found, firm $i$ has invested the amount $r_{i}$ in advance and has to bear these costs even if there is no production. Once the patent race is over, firm $i$ does not invest any resources. In this case the value of non-agreement is zero, whereas it is $-r_{i}$ in the first case.

3.1.2.1 No firm has found the innovation Consider again first the situation in which no innovation has occurred. Plugging (2.14) and (3.5) into (3.13) and taking into account that employment equals production $\left(x_{i}=l_{i}\right)$ we get:

$$
\Omega=\delta \ln \left(\left(w_{i}-\bar{w}\right)^{\theta} x_{i}\left(w_{i}, w_{j}\right)^{1-\theta}\right)+(1-\delta) \ln \left(x_{i}\left(w_{i}, w_{j}\right)^{2}\right)
$$

Setting the derivative of equation (3.14) with respect to $w_{i}$ zero gives the first order condition for the bargained wage. This can be solved for $w_{i}$ (see, the appendix A.2.2):

$$
w_{i}=\bar{w}+\frac{\theta \delta(2-\gamma)(\alpha-\bar{w})+\theta \delta \gamma\left(w_{j}-\bar{w}\right)}{2(2-\delta)}
$$

\footnotetext{
${ }^{11}$ Note again that there is no intertemporal effect of the bargain. Thus, we can again focus on a situation in which the utility and profit flow is maximised.
} 
This is the (wage) reaction curve of the union since both unions interact with each other via the strategic interdependence of "their" firms. Note that this game between both unions $i$ is played in strategic complements, i.e. a higher wage $w_{j}$ increases the wage $w_{i}$. The intuition is straightforward. A higher wage $w_{j}$ implies a strategic advantage of firm $i$ and thus, higher profits. The union in firm $i$ wants to participate from this strategic advantage and increases its wage demands.

The equilibrium wage in a situation in which no firm has become the innovator yet is given by:

$$
w_{i}=w_{j}=w=\bar{w}+\frac{\theta \delta(2-\gamma)}{2(2-\delta)-\theta \delta \gamma}(\alpha-\bar{w}),
$$

where we assume that $\alpha>\bar{w}$. If this was not the case the economy would break down since in the initial situation production would be too expensive.

3.1.2.2 Firm $i$ has won the patent race Consider the situation in which firm $i$ is the successful innovator. Plugging (2.14) and (3.11) into (3.13), with $\bar{\Pi}_{i}=0$ and taking into account that employment is only a part $\Delta$ of production $\left(\Delta x_{i}=l_{i}\right)$ gives:

$$
\Omega=\delta \ln \left(\left(w_{i}-\bar{w}\right)^{\theta}\left(\Delta x_{i}\right)^{1-\theta}\right)+(1-\delta) \ln \left(x_{i}\left(\Delta w_{i}, w_{j}\right)^{2}\right) .
$$

The wage curve in firm $i$ is thus given by

$$
w_{i}=\bar{w}+\frac{\theta \delta(2-\gamma)(\alpha-\Delta \bar{w})+\theta \delta \gamma\left(w_{j}-\Delta \bar{w}\right)}{2 \Delta(2-\delta)} .
$$

The bargained wage in firm $j$ (which lost the patent race) can be determined by maximising

$$
\Omega=\delta \ln \left(\left(w_{j}-\bar{w}\right)^{\theta}\left(x_{j}\right)^{1-\theta}\right)+(1-\delta) \ln \left(x_{j}\left(\Delta w_{i}, w_{j}\right)^{2}\right),
$$

which yields the following wage reaction curve (see, the appendix A.2.2)

$$
w_{j}=\bar{w}+\frac{\theta \delta(2-\gamma)(\alpha-\bar{w})+\theta \delta \gamma\left(\Delta w_{i}-\bar{w}\right)}{2(2-\delta)} .
$$

As long as union bargaining power $\delta$ is zero or the weight the union attaches to wages $\theta$ is zero, the innovation does not change the wage situation in the economy. 
The Nash equilibrium bargained wages can be derived using (3.18) and (3.20) (see the appendix A.2.2):

$$
\begin{gathered}
w_{i}=\frac{(2-\gamma) \delta \theta(2(2-\delta)+\theta \delta \gamma)}{|\mathbf{A}|} \alpha+\frac{2(2-\gamma(1+\theta))(2(2-\delta) \Delta+\theta \delta \gamma)}{|\mathbf{A}|} \bar{w} \\
w_{j}=\frac{(2-\gamma) \delta \theta \Delta(2(2-\delta)+\theta \delta \gamma)}{|\mathbf{A}|} \alpha+\frac{\Delta 2(2-\gamma(1+\theta))(2(2-\delta)+\theta \delta \gamma \Delta)}{|\mathbf{A}|} \bar{w} .
\end{gathered}
$$

Proposition 1 The wage in the firm that wins (looses) the patent race increases (decreases).

The productivity enhancing effect increases the strategic advantage of the innovative firm over the firm which lost the patent race. This strategic advantage implies two things 1.) opportunity costs of decreasing employment for the winning firm are high, i.e. the wage elasticity will be low and 2.) the profit of the winning firm will be high. Both makes the union to bargain for a higher wage in the innovative firm.

Plugging equilibrium wages (3.21) and (3.22) into equilibrium production (3.9) and (3.10) yields the effect of the labour saving innovation on output in both firms of the economy and thus, the effect on employment:

$$
\begin{aligned}
& x_{i}=\frac{1}{4-\gamma^{2}}\left((2-\gamma) \alpha-2 \Delta w_{i}(\Delta, .)+\gamma w_{j}(\Delta, .)\right), \\
& x_{j}=\frac{1}{4-\gamma^{2}}\left((2-\gamma) \alpha-2 w_{j}(\Delta, .)+\Delta \gamma w_{i}(\Delta, .)\right) .
\end{aligned}
$$

Proposition 2 The output of the innovating firm will unambiguously increase, whereas the output of the firm that has lost the patent race will unambiguously decrease.

Proof. Using the expression given in appendix A.2.2 for the equilibrium wage differential, it is easy to see that:

$$
\begin{aligned}
\frac{\partial x_{i}}{\partial \Delta} & =\frac{2(2-\delta(1+\theta))}{\left(4-\gamma^{2}\right)|\mathbf{A}|}\left(\delta\left(4+\theta \delta \gamma^{2}\right)-8\right) \bar{w} \leq 0 \\
\frac{\partial x_{j}}{\partial \Delta} & =\frac{2(2-\delta(1+\theta))}{\left(4-\gamma^{2}\right)|\mathbf{A}|}(2 \gamma(2-\delta(1+\theta))) \bar{w} \geq 0
\end{aligned}
$$


Let me give some intuition for proposition 2. Consider firm $i$ which has won the patent race. With a more efficient production process, firm $i$ is more competitive and gets a higher market share. On impact production increases. The union that bargains the wage in firm $i$ increases the bargained wage and hence, decreases employment and production. Firm $i$ faces two countervailing effects. However, the direct effect (increased competitiveness) always dominates the wage hike effect. Only in the case in which the union is a monopoly $(\delta=1)$ and only puts weight on wage increases $(\theta=1)$ the output of the winning firm does not change. The union captures all of the innovation rents.

Firm $j$ which lost the patent race looses market share and thus, decreases production. However, the union is willing to take some of the burden, i.e. it decreases its wage demands (since labour demand has become more elastic). However, this union effect will never overcompensate the initial loss in competitiveness. If $\delta=\theta=1$, i.e. the economy is characterised by a monopoly union which maximises the wage, the indirect and direct effect on the production of firm $j$ just cancel out with the consequence that firm $j$ does not loose market share although it lost the patent race.

In the public debate, it is sometimes put forward that innovation decreases employment in the economy, see for example Ulph and Ulph (1998). The employment effect of the innovation can be analysed using the results for the output effect of innovation.

Aggregate employment in the economy is (after firm $i$ has won the patent race and implemented the innovation):

$$
l=l_{i}+l_{j}=x_{i} \Delta+x_{j} .
$$

Firm $j$ has not the chance to implement the labour saving technology, thus the one to one relationship between employment and production is unchanged. Firm $i$ on the other hand introduced the labour saving technology. This implies that the amount of labour needed to produce $x_{i}$ declines by the fraction $\Delta$.

Aggregate employment changes due to three effects: 1.) output and hence, employment in firm $j$ decreases, 2.) the employment requirements in firm $i$ decreases and 3.) output in firm $i$ increases. Only the latter effect increases employment. More formally, this is:

$$
d l=\left(\frac{\partial x_{i}}{\partial \Delta}+x_{i}+\frac{\partial x_{j}}{\partial \Delta}\right) d \Delta \gtreqless 0 .
$$


Plugging in (3.25) and (3.26) and doing some algebraic manipulations gives:

$$
\frac{d l}{d \Delta}=(\frac{2(2-\delta(1+\theta))}{\left(4-\gamma^{2}\right)|\mathbf{A}|} \bar{w} \underbrace{\left(4(\gamma+\delta)-8+\theta \delta^{2} \gamma^{2}-2 \delta \gamma(1+\theta)\right)}_{<0}+x_{i}) \gtreqless 0 .
$$

Proposition 3 Employment (Unemployment) unambiguously decreases (increases) with an innovation

a.) if the outside option wage $\bar{w}$ is zero and

b.) if the economy is characterised by a monopoly union which is only interested in wage increases $\delta=\theta=1$.

In both situations the wage increase in the innovating firm and the wage decrease in the firm which lost the race are identical. This implies that with the wage adjustment of the union the strategic position of both firms remains unchanged and so is equilibrium output. Hence, only the labour saving effect survives and this unambiguously decreases employment. In the case of competitive labour markets, $\delta=0$, the employment effect of a labour saving innovation is ambiguous.

\subsubsection{Research Investment}

At the first stage of every period, each firm has to decide how much to invest into the research process, $r_{i}$, in order to win the patent race. At this stage the firm has rational expectations and anticipates what happens at the bargaining stage and at the production/competition stage.

Deriving the first order condition for the choice of $r_{i}$ using (2.13) yields: ${ }^{12}$

$$
\begin{gathered}
\frac{\partial P V_{i}}{\partial r_{i}}=\frac{\left(h^{\prime}\left(r_{i}\right) \Pi_{i}\left(\Delta w_{i}, w_{j}\right) \rho^{-1}-1\right)\left[\rho+h\left(r_{i}\right)+h\left(r_{j}\right)\right]}{\left(\rho+h\left(r_{i}\right)+h\left(r_{j}\right)\right)^{2}} \\
\frac{-h^{\prime}\left(r_{i}\right)\left[\Pi_{i}\left(w_{i}, w_{j}, r_{i}\right)+h\left(r_{i}\right) \Pi_{i}\left(\Delta w_{i}, w_{j}\right) \rho^{-1}+h\left(r_{j}\right) \Pi_{i}\left(w_{i}, \Delta w_{j}\right) \rho^{-1}\right]}{\left(\rho+h\left(r_{i}\right)+h\left(r_{j}\right)\right)^{2}}=0 \\
\Leftrightarrow h^{\prime}\left(r_{i}\right)\left(\Pi_{i}\left(\Delta w_{i}, w_{j}\right) \rho^{-1}-P V_{i}\right)=1
\end{gathered}
$$

\footnotetext{
${ }^{12}$ Equilibrium output and hence equilibrium profit is not affected by the choice of $r_{i}$.
} 
where the left-hand side of this equation depicts the (expected) marginal gain due to the increased investment in research. The marginal gain consists of the increased probability of making an innovation times the net value of being an innovator (i.e. the difference between the state value of being an innovator and the state of the patent race being open). The marginal loss associated with an increase in research expenditures depicts the right-hand side.

Equation (3.30) enables us to analyse the effects of unionisation, understood as an increase in bargaining power, on the optimal amount of research investment of the firm. Remember that, because unions bargain the wage at later stages, profits (independently of the innovative status) are a function of (inter alia) bargaining power $\delta$. Totally differentiating (3.30) in $r_{i}$ and $\delta$ gives:

$h^{\prime \prime}\left(r_{i}\right)\left(\Pi_{i}\left(\Delta w_{i}, w_{j}\right) \rho^{-1}-P V_{i}\right) d r+h^{\prime}\left(r_{i}\right)\left(\frac{\partial \Pi_{i}\left(\Delta w_{i}, w_{j}\right)}{\partial \delta} \rho^{-1}-\frac{\partial P V_{i}}{\partial \delta}\right) d \delta=0$.

Plugging in the expressions for $\Pi$ and $P V_{i}$ and taking advantage of the fact that we consider a symmetric equilibrium in which $r_{i}=r_{j}=r$ yields:

$$
\begin{array}{r}
\underbrace{-\frac{h^{\prime \prime}(r)}{h^{\prime}(r)}\left(\Pi_{i}\left(\Delta w_{i}, w_{j}\right) \rho^{-1}-P V\right)}_{>0} \frac{d r}{d \delta}= \\
2 \rho^{-1}\left(1-\frac{h(r)}{\rho+2 h(r)}\right) \frac{\partial x_{i}\left(\Delta w_{i}, w_{j}\right)}{\partial \delta} x_{i}\left(\Delta w_{i}, w_{j}\right) \\
-2 \rho^{-1} \frac{h(r)}{\rho+2 h(r)} \frac{\partial x_{i}\left(w_{i}, \Delta w_{j}\right)}{\partial \delta} x_{i}\left(w_{i}, \Delta w_{j}\right) \\
-2 \frac{\partial x}{\partial \delta} x
\end{array}
$$

Equation (3.32) depicts the three different, possibly countervailing, effects of unionisation on optimal research investment.

1. The first effect is the well-known hold-up problem as for example formalised by Grout (1984) or Ploeg (1987). In case the firm is the winner of the patent race, the union is able to capture some of the innovation rent and thus could ceteris paribus decrease output and profits. This decreases the incentive for the firm to invest resources into the patent race. 
2. The second effect is due to the impact of unionisation in the case of loosing the patent race. In this case (increased) unionisation could also decrease profits. This, however, increases the incentive to invest into research since the only way to escape this threat is to become the innovator (Ulph and Ulph (1998) refer to this as the competitive threat).

3. The third effect refers to the profit flow during the race. In this case unionisation decreases profits, too. Thus, unionisation is more costly, the longer the race takes. With this the incentive to shorten the race, i.e. invest more resources into the research process increases ("negative" Arrow effect).

The model is characterised by a complex strategic structure since there is oligopolistic competition in the goods market as well as in the market of the upstream supplier (the union). Both interact with each other and hence, influence the investment decision. We are not able to determine algebraically the sign of the net effect of unionisation on the investment decision of the firm. Instead, we will present a numerical simulation of the model which shows the effect of bargaining power on optimal research investment and which depicts how this relation changes due to a change in product heterogeneity.

Consider an economy which is characterised by the following research process $h(r)=\left(1-(1+r)^{-\omega}\right)$ and by the following parameter vector $\{\bar{w}=$ $1, \alpha=8 \bar{w}, \rho=0.015, \Delta=0.9, \omega=0.5\} .{ }^{13}$ With this we are able to calculate optimal research investment as a function of bargaining power. ${ }^{14}$. The result of these calculations is shown in figure 3. The thick, dashed (thin, straight) line is optimal research investment as a function of bargaining power in the case of $\gamma=0(\gamma=1)$.

Proposition 4 Research investment in the situation with two monopolists $(\gamma=0)$ is larger than in the homogenous duopoly case $(\gamma=1)$.

This seems counterintuitive, but this property is due to the fact that a decrease in $\gamma$ has two different effects. First, the profit when being the innovator

\footnotetext{
${ }^{13}$ The form of the research process we consider has the unfavourable property that since $h^{\prime}(0)<\infty$ situations exist in which the marginal incentive to invest is smaller than the marginal costs. We only consider parameter values which rule out these corner solutions. The reason why we have to stick to this research process is purely of technical nature.

${ }^{14}$ All calculations have been performed with Mathematica ${ }^{\circledR}$ 5.1. The notebooks are available upon request.
} 


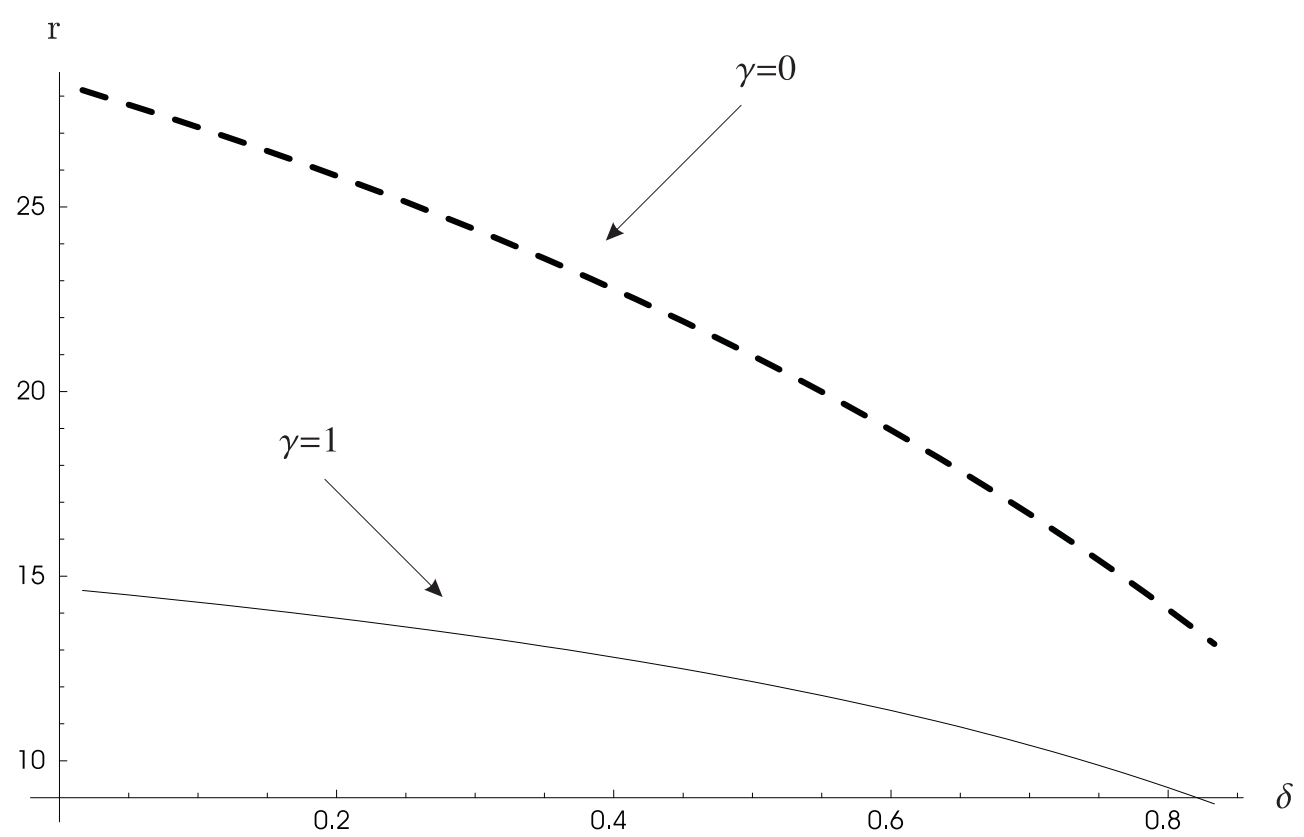

Figure 3: The impact of Unionisation on R\&D Investment - Right-to-manage

increases (since there will be less competition). Second, the value of not having innovated (i.e. the present value) increases, too. However, the first effect dominates since the effect of less competition on the present value are of second-order due to discounting.

Proposition 5 The effect of unionisation (=increased bargaining power) on optimal research investment is negative, independent of the degree of heterogeneity of the duopoly.

The direct hold-up effect is never compensated by the Arrow effect or the strategic effect. Given a certain amount of bargaining power, the Arrow effect increases with a decrease in $\gamma$, however, the strategic effect decreases. Hence, if unionisation decreases research investment in the situation of a homogenous duopoly, this will also be true when the economy moves to the polar case of two monopolists. This generalises results found for example in Ulph and Ulph (1994).

Although the different market structure (in the form of different $\gamma$ ) does not affect the qualitative effects of unionisation on equilibrium research in- 
vestment, it has however quantitative effects. The strength of an increase in unionisation is larger in the case of $\gamma=0$ than in the case of a homogenous duopoly. ${ }^{15}$ We have argued above that the positive incentive effects of union wage bargaining is hardly affected by changes in $\gamma$. This is due to the fact that for example an increase in $\gamma$ increases the strategic effect, but at the same time decreases the Arrow effect. Thus, the hold-up effect is the main driving force for unionisation to affect research. But this increases with a decrease in $\gamma$, hence the union effect is stronger with $\gamma=0$ compared to a situation of $\gamma=1$.

\subsection{Efficient Bargaining}

\subsubsection{The Production Decision}

In a situation in which the union and the firm efficiently bargain over wages and employment, the firm cannot unilaterally decide over production as in the previous section. In contrast equilibrium production will be determined via the maximisation of a Nash product. As in the right-to-manage case we have to distinguish situations in which no firm has found an innovation and situations in which the patent race is over, i.e. one firm has won the race.

3.2.1.1 No firm has found the innovation Assuming union utility and bargaining power to be the same as in the situation with the right-tomanage regime, the Nash product reads:

$$
\Omega=\left(V_{i}\left(w_{i}, l_{i}\right)\right)^{\delta}\left(\left(p_{i}\left(x_{i}, x_{j}\right)-w_{i}\right) l_{i}\right)^{(1-\delta)},
$$

where the outside option of the union is $\bar{V}_{i}=0$ and the outside option of the firm is $\bar{\Pi}_{i}=-r_{i}$. During the bargain the union as well as the firm take the price effect into account and assume the output of the other oligopolist as given (=Nash equilibrium).

Bargained employment (=production) in this case is given by (see, appendix A.3.1):

$$
x_{i}=\chi_{1}^{-1}\left(\alpha-\gamma x_{j}-w_{i}\right),
$$

where $\chi_{1}:=\left(1+\frac{1-\delta}{1-\delta \theta}\right)$ which is the reaction function of the firm in the efficient bargaining case. Note that this reaction function is identical to the

\footnotetext{
${ }^{15}$ The slope of the dashed line exceeds that of the straight line. Note that we do not have to rely to this "eye-ball" proof, but have numerically simulated the different slopes. We skipped these results for lack of space, however they are available on request.
} 
one in the right-to-manage situation for $\chi_{i}^{-1}=0.5$. This is the case with union bargaining power $\delta$ equal to zero. With any positive bargaining power $\chi_{1}^{-1}$ will exceed 0.5 . Thus, output would ceteris paribus increase with efficient bargaining. This is due to the fact that employment is not restrained by the labour demand curve, but will be on the contract curve (see, e.g. Booth (1995)).

Using the reaction curves, we can determine equilibrium output under efficient bargaining:

$$
\begin{aligned}
x_{i} & =\frac{1}{\chi_{1}^{2}-\gamma^{2}}\left(\left(\chi_{1}-\gamma\right) \alpha-\chi_{1} w_{i}+\gamma w_{j}\right) \\
x_{j} & =\frac{1}{\chi_{1}^{2}-\gamma^{2}}\left(\left(\chi_{1}-\gamma\right) \alpha-\chi_{1} w_{j}+\gamma w_{i}\right) .
\end{aligned}
$$

Equilibrium profit of firm $i$ is hence (using the endogenous demand relation and equilibrium output):

$$
\Pi_{i}\left(w_{i}, w_{j}, r_{i}\right)=\left(\chi_{1}-1\right) x_{i}^{2}-r_{i} .
$$

Equations (3.34) and (3.37) depict two properties which distinguish the situation of firms in the efficient bargaining case from that with right-to-manage. First, since $\chi_{1}^{-1}>0.5$ the reaction curve of the firm will be steeper in the efficient bargaining case. Second, operating profits is not squared output, but only a part of it. Additionally, this share which the firm can keep is decreasing in union bargaining power $\delta$.

3.2.1.2 Firm $i$ has won the patent race In the case of firm $i$ being the winner of the patent race, the production function in this firm changes to $x_{i}=\Delta^{-1} l_{i}$. Consequently, the Nash product for the determination of bargained employment changes to:

$$
\Omega=\left(V_{i}\left(w_{i}, l_{i}\right)\right)^{\delta}\left(\left(p_{i}\left(x_{i}, x_{j}\right) \Delta^{-1}-w_{i}\right) l_{i}\right)^{(1-\delta)} .
$$

The reaction function for the firm which won the patent race is given by:

$$
x_{i}=\chi_{1}^{-1}\left(\alpha-\gamma x_{j}-\Delta w_{i}\right) .
$$

The reaction function for firm $j$ is not affected by the discovery of the innovation and is thus given by (an appropriate modification of) (3.34). 
As such, equilibrium output is:

$$
\begin{aligned}
x_{i} & =\frac{1}{\chi_{1}^{2}-\gamma^{2}}\left(\left(\chi_{1}-\gamma\right) \alpha-\chi_{1} \Delta w_{i}+\gamma w_{j}\right) \\
x_{j} & =\frac{1}{\chi_{1}^{2}-\gamma^{2}}\left(\left(\chi_{1}-\gamma\right) \alpha-\chi_{1} w_{j}+\gamma \Delta w_{i}\right) .
\end{aligned}
$$

In this case, the equilibrium (flow) profit of the firm that won and lost the patent race, respectively, is given by:

$$
\begin{aligned}
& \Pi_{i}\left(\Delta w_{i}, w_{j}\right)=\left(\chi_{1}-1\right) x_{i}\left(\Delta w_{i}, w_{j}\right)^{2}, \\
& \Pi_{j}\left(w_{j}, \Delta w_{i}\right)=\left(\chi_{1}-1\right) x_{j}\left(w_{j}, \Delta w_{i}\right)^{2} .
\end{aligned}
$$

\subsubsection{Union Wage Bargaining}

The union and the firm simultaneously bargain employment and the wage. During the wage bargain, employment can be assumed fixed (in order to determine a Nash equilibrium). This is true since employment and wage combinations need not to be on the labour demand curve.

3.2.2.1 No firm has found the innovation The Nash product which is used to determine the bargained wage is the same as in the previous section, given by (3.33). Maximisation yields the bargained wage in firm $i$ (see appendix A.3.2).

$$
w_{i}=\bar{w}+\frac{\delta \theta\left(\chi_{1}-\gamma\right)(\alpha-\bar{w})+\delta \theta \gamma\left(w_{j}-\bar{w}\right)}{\left(\chi_{1}^{2}-\gamma^{2}\right)(1-\delta \theta)+\chi_{1} \delta \theta} .
$$

The bargained wage will be a mark-up on the outside wage $\bar{w}$. This is similar to the right-to-manage case. However, it is ambiguous whether the bargained wage will be smaller or larger than that of the right-to-manage case.

The wage reaction curves determine the equilibrium wages which are:

$$
w=w_{i}=w_{j}=\bar{w}+\frac{\delta \theta\left(\chi_{1}-\gamma\right)(\alpha-\bar{w})}{\left(\chi_{1}^{2}-\gamma^{2}\right)(1-\delta \theta)+\delta \theta\left(\chi_{1}-\gamma\right)} .
$$

With the wages being identical in the two firms, employment will be identical, too. This is at least true as long as no innovation has been found. 
3.2.2.2 Firm $i$ has won the race To find the bargained wage in firm $i$, we have to maximise the Nash product (3.38) with respect to the wage $w_{i}$. This yields:

$$
\Delta w_{i}=\Delta \bar{w}+\frac{\delta \theta\left(\chi_{1}-\gamma\right)(\alpha-\Delta \bar{w})+\delta \theta \gamma\left(w_{j}-\Delta \bar{w}\right)}{\left(\chi_{1}^{2}-\gamma^{2}\right)(1-\delta \theta)+\chi_{1} \delta \theta} .
$$

As in the previous section, it is again true that the Nash product for the firm that lost the patent race does not change. Nevertheless, the wage reaction curve is affected by the innovation. Output (and as such profits) of firm $j$ decreases with firm $i$ implementing the superior technology. Thus, the size of the pie which could be shared between firm and union decreases. This is taken into account by the union. The bargained wage will be given by (see, appendix A.3.2):

$$
w_{j}=\bar{w}+\frac{\delta \theta\left(\chi_{1}-\gamma\right)(\alpha-\bar{w})+\delta \theta \gamma\left(\Delta w_{i}-\bar{w}\right)}{\left(\chi_{1}^{2}-\gamma^{2}\right)(1-\delta \theta)+\chi_{1} \delta \theta} .
$$

Both wage reaction functions can be solved for equilibrium wages:

$$
\begin{gathered}
w_{i}=\frac{\left(\chi_{1}-\gamma\right) \delta \theta\left(\chi_{2}+\delta \theta \gamma\right)}{|\mathbf{B}|} \alpha+\frac{\left(\chi_{1}^{2}-\gamma^{2}\right)(1-\delta \theta)\left(\chi_{2} \Delta+\delta \theta \gamma\right.}{|\mathbf{B}|} \bar{w} \\
w_{j}=\frac{\Delta\left(\chi_{1}-\gamma\right) \delta \theta\left(\chi_{2}+\delta \theta \gamma\right)}{|\mathbf{B}|} \alpha+\frac{\Delta\left(\chi_{1}^{2}-\gamma^{2}\right)(1-\delta \theta)\left(\chi_{2}+\delta \theta \gamma \Delta\right)}{|\mathbf{B}|} \bar{w} .
\end{gathered}
$$

The structure of the equilibrium is identical to the one in the right-tomanage framework. Equilibrium wages determine equilibrium employment which in turn determines equilibrium output. Comparative static results in the efficient bargaining case are by and large identical to the ones in the previous section.

Proposition 6 With efficient bargaining, the wage in the firm that won (lost) the patent race increases (decreases). This effect is the stronger the larger the efficiency effect of the innovation is.

Proof. Straightforward by differentiation of (3.48) and (3.49) with respect to $\Delta$.

Using equilibrium wages and equilibrium production, we are able to determine the output effects of innovation in each firm and we can analyse the effect on aggregate employment. As in the economy with union wage bargaining and right-to-manage, we get the following: 
Proposition 7 Output in the winning firm increases whereas it decreases in the firm which lost the patent race.

Proof. With the help of equations (A.60) and (A.61) it is easy to see that:

$$
\begin{gathered}
\frac{\partial x_{i}}{\partial \Delta}=\frac{\Delta(1-\delta \theta)}{|\mathbf{B}|}\left(\delta \theta \gamma^{2}-\chi_{1} \chi_{2}\right) \leq 0 \\
\frac{\partial x_{j}}{\partial \Delta}=\frac{\Delta(1-\delta \theta)}{|\mathbf{B}|}\left(\chi_{2} \delta-\delta \theta \gamma \chi_{1}\right) \geq 0
\end{gathered}
$$

Since the change in aggregate employment in the situation in which firm $i$ won the patent race is given by:

$$
d l=\left(\frac{\partial x_{i}}{\partial \Delta}+x_{i}+\frac{\partial x_{i}}{\partial \Delta}\right)
$$

we can use the result of proposition 7 and get after some manipulations an expression for the change in employment caused by an innovation:

$$
\frac{d l}{d \Delta}=\frac{\Delta(1-\delta \theta)}{|\mathbf{B}|} \underbrace{\left(\delta \theta \gamma^{2}+\chi_{2} \delta-\chi_{1} \chi_{2}-\delta \theta \gamma \chi_{1}\right) \bar{w}}_{<0}+x_{i} \gtreqless 0 .
$$

The aggregate employment effect of an innovation again is ambiguous. But with equation (3.50) it is easy to see that the results from proposition 3 also hold true with efficient bargaining.

\subsubsection{Research Investment}

The research investment decision does not change in the efficient bargaining case compared to the right-to-manage situation. Also in this case, equation (3.30) must hold and the union has the same general effects as put forward in equation (3.32). Again, we cannot analytically solve for equilibrium R\&D investment and have to rely to a numerical simulation. Using the same parameter vector as in the previous section with right-to-manage yields a relation between $r$ and $\delta$ for $\gamma=0$ and $\gamma=1$ as shown in figure 4 . Note that this relation is unaffected by changes in $\gamma$.

Concerning the R\&D effects of union wage bargaining, the efficient bargaining case exhibits the same results as the right-to-manage case. However, 


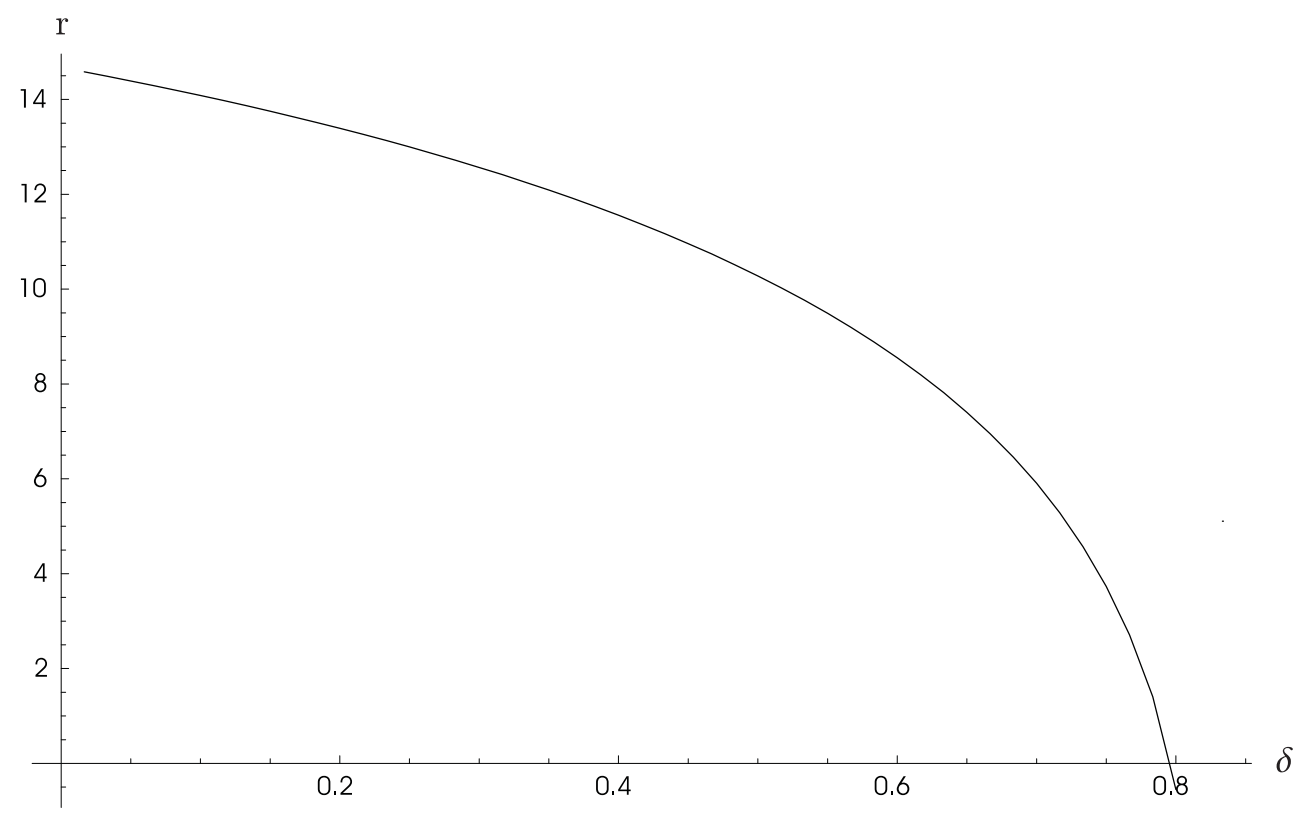

Figure 4: The Impact of Unionisation on R\&D Investment - Efficient Bargaining

there is one exception. The effects are qualitatively and quantitatively independent of the goods market situation. This is because the union will capture all of the additional monopoly rents generated by a larger product heterogeneity. Thus, profits (in any case) do not change with a change in $\gamma$. The same is true for optimal investment into R\&D.

Using the simulation for research investment with right-to-manage and with efficient bargaining, we can compare a.) the effect of the different bargaining institutions on optimal research investment and b.) the effect of an increase of bargaining power within the different institutional settings. This is done in figure 5 assuming $\gamma=1$.

Proposition 8 Research investment in the right-to-manage case will in general exceed that of the efficient bargaining case. Only with no unionisation investment decision will be identical within both institutional settings.

At first glance, this proposition is counter-intuitive since output in the effi- 


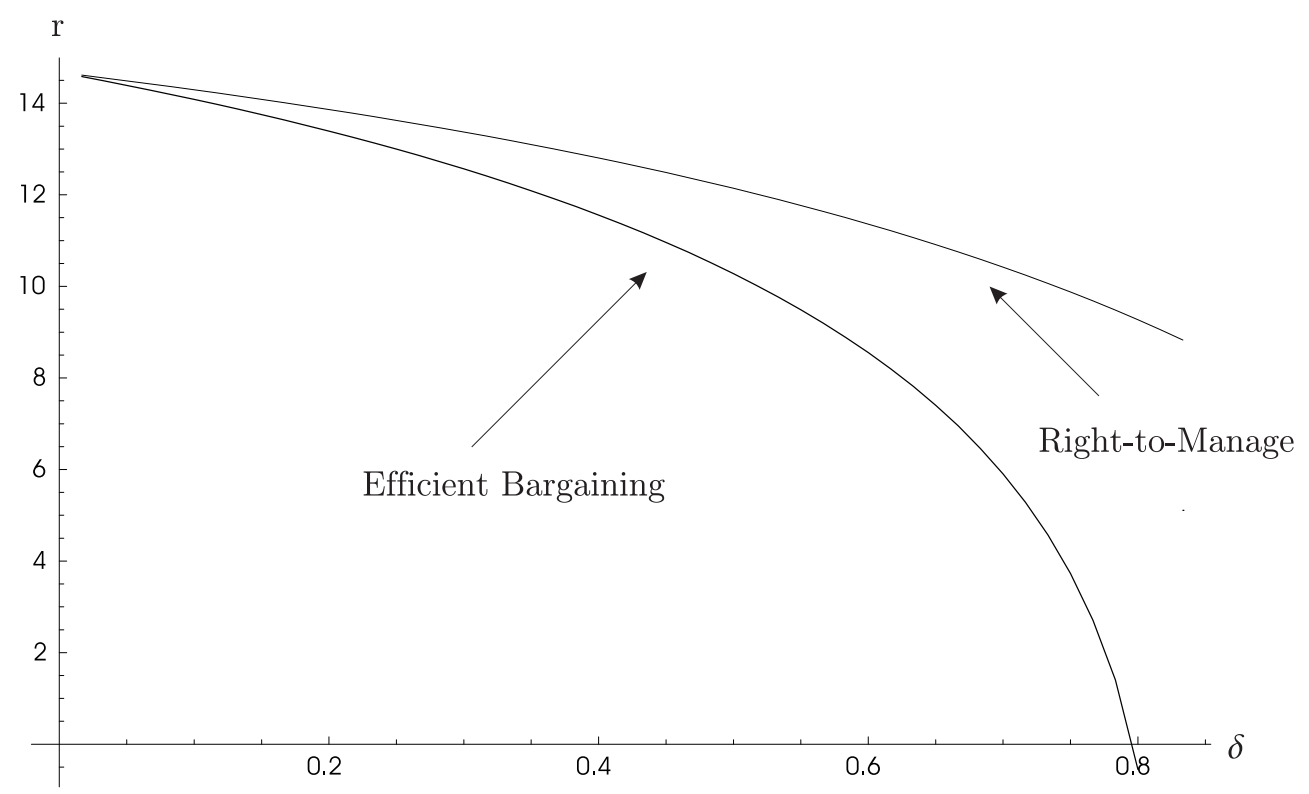

Figure 5: The Impact of Unionisation on R\&D Investment - Right-to-Manage vs. Efficient Bargaining

cient bargaining case is larger than in the right-to-manage situation. ${ }^{16}$ However, the union is able to bargain for a larger piece of the pie. Thus, although there is an output expansion, the profit in the efficiency bargaining case is smaller than that in the right to manage framework. This decreases the incentive to invest into R\&D.

Proposition 9 Unionisation, i.e. increased bargaining power, has larger effects on research investment in the efficient bargaining than in the right-tomanage case.

The different strength of unionisation under efficient bargaining compared to a right-to-manage setting is due to the fact that the hold-up effect in the efficient bargaining case is stronger compared with right-to-manage. An increase in $\delta$ has a direct effect on profits by increasing the wage demands of the union. In addition an increase in $\delta$ also implies that firms only get

\footnotetext{
${ }^{16}$ With efficient bargaining, points on the contract curve will be realised. With StoneGeary preferences, this will be positively sloped, hence for all $w>\bar{w}$ employment will be larger compared to situations on the labour demand curve, see for example Booth (1995).
} 
a smaller share of produced output as profit. This is true independently of whether the firm won or lost the patent race or no innovation has occurred. Thus, the disincentive effect of unionisation in the efficient bargaining case is stronger than with right-to-manage.

\section{Summary and Conclusion}

This paper researches into the question of the effect of union wage bargaining on the firm's incentive to invest into $R \& D$. We use a framework with two dupolists who produce heterogeneous goods, invest resources into research and bargain the wage with the upstream supplier, the labour union. The model accounts for different institutional bargaining frameworks, namely right-to-manage and efficient bargaining. The R\&D investment is modelled as a patent race during which each firm invests resources to find a productivity enhancing technology. Once this is found the patent race ends and the winning firm is protected by an infinitely lasting patent.

We identify three channels through which union wage bargaining affects the incentive for performing research. The union gives rise to a hold-up problem since it will capture some of the innovation rents. This effect is negative. However, the existence of the union strengthens the strategic incentive to perform an innovation. Loosing the patent race is less "attractive" than without union wage bargaining. This effect is positive. Additionally, the union gives rise to a third effect which is again positive. The union decreases the profit of the firm during the patent race and hence decreases the replacement or Arrow effect. This latter effect has not been clearly identified in the literature we are aware of.

The overall effect of unionisation on R\&D investment cannot analytically be determined within the model. As such, we have to rely on numerical simulations. Nevertheless, this numerical exercise offers some interesting insights on the relative strength of the different union effects.

The central result of the paper is that union wage bargaining will unambiguously decrease the amount of resources which firms want to invest into the research process. Thus, the hold-up effect always dominates. This is even true for the extreme case in which we consider two monopolists. The Arrow effect will be very strong in this situation, however, as product heterogeneity increases, the strategic incentive for performing research decreases. In sum, the hold-up effect of the union always dominates. 
Another interesting question that comes up is whether a different institutional bargaining set-up affects the results concerning $R \& D$ investment. To analyse this, we have simulated the effect of increased bargaining power in a setting with right-to-manage and one with efficient bargaining. Qualitative, both institutional settings yield the same results, however quantitatively they perform differently. The negative effect of union wage bargaining in the efficient bargaining case will be larger than in the right-to-manage situation. This is because with efficient bargaining the hold-up problem is much more severe than in the right-to-manage situation.

The whole analysis has been performed within a framework in which firms behave Cournot-like and only set quantities. We know, however, that the effect of union wage bargaining on firm profits are not symmetric between Cournot and Bertrand behaviour. As such, it would be interesting to analyse the effect of union wage bargaining on the incentive to perform research in a setting in which firms behave Bertrand-like. Moreover, it would be interesting to analyse whether product heterogeneity and considering the Arrow effect would modify the results concerning centralisation, as analysed in Haucap and Wey (2004). We leave these questions for further research.

\section{References}

[1] Agell, Jonas and Lommerud, Kjell Erik, (1993), Egalitarianism and Growth, Scandinavian Journal of Economics, December 1993, v. 95, iss. 4, pp. 559-79.

[2] Booth, Alison L., (1995), The economics of the trade union, 1995, pp. xvi, 295, Cambridge; New York and Melbourne: Cambridge University Press.

[3] Dixit, Avinash, (1979), A Model of Duopoly Suggesting a Theory of Entry Barriers, Bell Journal of Economics, Spr. 1979, v. 10, iss. 1, pp. 20-32.

[4] Grout, Paul A., (1984), Investment and Wages in the Absence of Binding Contracts: A Nash Bargining Approach, Econometrica, March 1984, v. 52, iss. 2, pp. 449-60.

[5] Haucap, Justus and Wey, Christian, (2004), Unionisation Structures and Innovation Incentives, Economic Journal, March 2004, v. 114, iss. 494, pp. C149-65. 
[6] Lopez, Monica Correa and Naylor, Robin A., (2004), The CournotBertrand Profit Differential: A Reversal Result in a Differentiated Duopoly with Wage Bargaining, European Economic Review, June 2004, v. 48, iss. 3, pp. 681-96.

[7] Menezes-Filho, Naercio and Van Reenen, John, (2003), Unions and Innovation: A Survey of the Theory and Empirical Evidence, International handbook of trade unions, 2003, pp. 293-334, Cheltenham, U.K. and Northampton, Mass.: Elgar.

[8] Menezes-Filho, Naercio, Ulph, David and Van Reenen, John, (1998) The Determination of R\&D: Empirical Evidence on the Role of Unions, European Economic Review, May 1998, v. 42, iss. 3-5, pp. 919-30.

[9] Oswald, Andrew J., (1985), The Economic Theory of Trade Unions: An Introductory Survey, Scandinavian Journal of Economics, 1985, v. 87, iss. 2, pp. 160-93.

[10] Ploeg, Frederic van der, (1987), Trade Unions, Investment, and Employment: A Non-cooperative Approach, European Economic Review, October 1987, v. 31, iss. 7, pp. 1465-92.

[11] Reinganum, Jennifer F., (1983), Uncertain Innovation and the Persistence of Monopoly, American Economic Review, September 1983, v. 73, iss. 4 , pp. 741-48.

[12] Singh, Nirvikar and Vives, Xavier, (1984), Price and Quantity Competition in a Differentiated Duopoly, RAND Journal of Economics, Winter 1984, v. 15, iss. 4, pp. 546-54.

[13] Tirole, Jean, (1988), The theory of industrial organization, 1988, pp. xii, 479, Cambridge, Mass. and London: MIT Press.

[14] Ulph, Alistair and Ulph, David, (2001), Strategic Innovation with Complete and Incomplete Labour Market Contracts, Scandinavian Journal of Economics, June 2001, v. 103, iss. 2, pp. 265-82.

[15] Ulph, Alistair and Ulph, David, (1998), Labour Markets, Bargaining and Innovation, European Economic Review, May 1998, v. 42, iss. 3-5, pp. 931-39. 
[16] Ulph, A. M. and Ulph, D. T., (1994), Labour Markets and Innovation: Ex-Post Bargaining, European Economic Review, January 1994, v. 38, iss. 1, pp. 195-210.

A referee's appendix is available on request from:

joerg. lingens@wiwi.uni-regensburg.de 


\section{A Referees Appendix}

\section{A.1 The Linear Demand System}

Consumers choose the amounts of $x_{1}, x_{2}$ and $x_{3}$ which maximise the utility function s.t. the budget constraint $Y=p_{1} x_{1}+p_{2} x_{2}+x_{3}$. The optimal choice problem is solved using standard maximisation techniques:

$\mathcal{L}=\alpha\left(x_{1}+x_{2}\right)-\left(\beta\left(x_{1}^{2}+x_{2}^{2}\right)+2 \gamma x_{1} x_{2}\right) / 2+x_{3}+\lambda\left(Y-p_{1} x_{1}-p_{2} x_{2}-x_{3}\right)$.

This gives rise to the following foc:

$$
\begin{gathered}
\frac{\partial \mathcal{L}}{\partial x_{1}}=\alpha-x_{1}-\gamma x_{2}-\lambda p_{1}=0 \\
\frac{\partial \mathcal{L}}{\partial x_{2}}=\alpha-x_{2}-\gamma x_{1}-\lambda p_{2}=0 \\
\frac{\partial \mathcal{L}}{\partial x_{3}}=1-\lambda=0 \\
\frac{\partial \mathcal{L}}{\partial \lambda}=Y-p_{1} x_{1}-p_{2} x_{2}-x_{3}=0
\end{gathered}
$$

Using equations (A.2)-(A.4) gives the linear inverse demand system stated in the text.

\section{A.2 Right-to-Manage Equilibrium}

\section{A.2.1 Production Decision}

\section{A.2.1.1 No Firm has found the Innovation}

$$
\begin{aligned}
\Pi_{i} & =\left(p_{i}-w_{i}\right) x_{i}-r_{i}, \\
\Leftrightarrow \Pi_{i}\left(w_{i}, w_{j}\right) & =\left(\alpha-x_{i}-\gamma x_{j}-w_{i}\right) x_{i}-r_{i} .
\end{aligned}
$$

Maximising this with respect to $x_{i}$ gives:

$$
\begin{gathered}
\frac{\partial \prod_{i}\left(w_{i}, w_{j}\right)}{\partial x_{i}}=-x_{i}+\alpha-x_{i}-\gamma x_{j}-w_{i}=0 \\
\Leftrightarrow x_{i}=0.5\left(\alpha-\gamma x_{j}-w_{i}\right)
\end{gathered}
$$

The two reaction curves in matrix notation read:

$$
\left(\begin{array}{ll}
2 & \gamma \\
\gamma & 2
\end{array}\right)\left(\begin{array}{l}
x_{i} \\
x_{j}
\end{array}\right)=\left(\begin{array}{c}
\alpha-w_{i} \\
\alpha-w_{j}
\end{array}\right)
$$


The solution to this equilibrium system is given by:

$$
\begin{aligned}
x_{i} & =\frac{1}{4-\gamma^{2}}\left((2-\gamma) \alpha-2 w_{i}+\gamma w_{j}\right) \\
x_{j} & =\frac{1}{4-\gamma^{2}}\left((2-\gamma) \alpha-2 w_{j}+\gamma w_{i}\right),
\end{aligned}
$$

which is the equation stated in the text as (3.3) and (3.4). Using the equation for inverse demand (2.2) and the equation for equilibrium output, we can determine equilibrium profits as function of the wage.

\section{A.2.1.2 Firm $i$ has discovered the Innovation}

$$
\begin{gathered}
\Pi_{i}\left(\Delta w_{i}, w_{j}\right)=\left(p_{i}-\Delta w_{i}\right) x_{i}, \\
\Leftrightarrow \prod_{i}\left(\Delta w_{i}, w_{j}\right)=\left(\alpha-x_{i}-\gamma x_{j}-\Delta w_{i}\right) x_{i} .
\end{gathered}
$$

Maximising this with respect to $x_{i}$ gives:

$$
\begin{gathered}
\frac{\partial \prod_{i}\left(\Delta w_{i}, w_{j}\right)}{\partial x_{i}}=-x_{i}+\alpha-x_{i}-\gamma x_{j}-\Delta w_{i}=0 \\
\Leftrightarrow x_{i}=0.5\left(\alpha-\gamma x_{j}-\Delta w_{i}\right)
\end{gathered}
$$

Firm $j$ maximises:

$$
\begin{gathered}
\Pi_{j}\left(w_{j}, \Delta w_{i}\right)=\left(p_{j}-w_{j}\right) x_{j}, \\
\Leftrightarrow \prod_{i}\left(w_{j}, \Delta w_{i}\right)=\left(\alpha-x_{j}-\gamma x_{i}-w_{j}\right) x_{j} .
\end{gathered}
$$

Maximising this w.r.t. to $x_{j}$ gives:

$$
\begin{gathered}
\frac{\partial \Pi_{j}\left(w_{j}, \Delta w_{i}\right)}{\partial x_{i}}=-x_{j}+\alpha-x_{j}-\gamma x_{i}-w_{j}=0 \\
\frac{\partial \prod_{j}\left(w_{j}, \Delta w_{i}\right)}{\partial x_{i}}=-x_{j}+p_{j}-w_{j}=0 \\
\Leftrightarrow x_{j}=0.5\left(\alpha-\gamma x_{i}-w_{j}\right)
\end{gathered}
$$

The two reaction curves in matrix notation now read:

$$
\left(\begin{array}{ll}
2 & \gamma \\
\gamma & 2
\end{array}\right)\left(\begin{array}{l}
x_{i} \\
x_{j}
\end{array}\right)=\left(\begin{array}{c}
\alpha-\Delta w_{i} \\
\alpha-w_{j}
\end{array}\right)
$$


Solving this gives:

$$
\begin{aligned}
& x_{i}=\frac{1}{4-\gamma^{2}}\left((2-\gamma) \alpha-2 \Delta w_{i}+\gamma w_{j}\right) \\
& x_{j}=\frac{1}{4-\gamma^{2}}\left((2-\gamma) \alpha-2 w_{j}+\Delta \gamma w_{i}\right),
\end{aligned}
$$

which is (3.9) and (3.10) in the text.

\section{A.2.2 Wage Bargaining}

\section{A.2.2.1 No Firm has found the Innovation}

$$
\begin{gathered}
\frac{\partial \Omega}{\partial w_{i}}=\delta \frac{1}{V_{i}}\left(\theta\left(w_{i}-\bar{w}\right)^{\theta-1} x_{i}^{1-\theta}+(1-\theta) x_{i}^{-\theta} \frac{\partial x_{i}}{\partial w_{i}}\left(w_{i}-\bar{w}\right)^{\theta}\right) \\
+(1-\delta) \frac{1}{x_{i}^{2}} 2 x_{i} \frac{\partial x_{i}}{\partial w_{i}}=0 \\
\Leftrightarrow \frac{\partial \Omega}{\partial w_{i}}=\delta\left(\theta \frac{w_{i}}{w_{i}-\bar{w}}+(1-\theta) \frac{\partial x_{i}}{\partial w_{i}} \frac{w_{i}}{x_{i}}\right)+2(1-\delta) \frac{\partial x_{i}}{\partial w_{i}} \frac{w_{i}}{x_{i}}=0 \\
\Leftrightarrow \delta \theta \frac{w_{i}}{w_{i}-\bar{w}}+((1-\theta) \delta+2(1-\delta))\left(-\frac{2}{4-\gamma^{2}} \frac{w_{i}}{\left(4-\gamma^{2}\right)^{-1}\left((2-\gamma) \alpha-2 w_{i}+\gamma w_{j}\right)}\right)=0 \\
\Leftrightarrow w_{i}=\bar{w}+\frac{\theta \delta\left((2-\gamma) \alpha-2 w_{i}+\gamma w_{j}\right)}{2(2-\delta-\delta \theta)} \\
w_{i}\left(1+\frac{\theta \delta}{(2-\delta-\delta \theta)}\right)=\bar{w}+\frac{\theta \delta(2-\gamma) \alpha+\theta \delta \gamma w_{j}}{2(2-\delta-\delta \theta)} \\
w_{i}=\frac{2-\delta-\delta \theta}{2-\delta} \bar{w}+\frac{\theta \delta(2-\gamma) \alpha+\theta \delta \gamma w_{j}}{2(2-\delta)} \\
w_{i}=\bar{w}+\frac{\theta \delta(2-\gamma)(\alpha-\bar{w})+\theta \delta \gamma\left(w_{j}-\bar{w}\right)}{2(2-\delta)}, \quad(\mathrm{A} .27)
\end{gathered}
$$

i.e. the wage is a mark-up over some alternative income. The mark-up inter alia is a function of the bargaining power and the wage elasticity of labour demand. This is exactly the same wage equation as in Lopez and Naylor (2004). 


\section{A.2.2.2 Firm i has discovered the Innovation}

$$
\begin{gathered}
\frac{\partial \Omega}{\partial w_{i}}=\delta \frac{1}{V_{i}}\left(\theta\left(w_{i}-\bar{w}\right)^{\theta-1}\left(\Delta x_{i}\right)^{1-\theta}+(1-\theta)\left(\Delta x_{i}\right)^{-\theta} \Delta \frac{\partial x_{i}}{\partial w_{i}}\left(w_{i}-\bar{w}\right)^{\theta}\right) \\
+(1-\delta) \frac{1}{x_{i}^{2}} 2 x_{i} \frac{\partial x_{i}}{\partial w_{i}}=0 \\
\Leftrightarrow \frac{\partial \Omega}{\partial w_{i}}=\delta\left(\theta \frac{w_{i}}{w_{i}-\bar{w}}+(1-\theta) \frac{\partial x_{i}}{\partial w_{i}} \frac{w_{i}}{x_{i}}\right)+2(1-\delta) \frac{\partial x_{i}}{\partial w_{i}} \frac{w_{i}}{x_{i}}=0 \quad(\mathrm{~A} .30) \\
\Leftrightarrow \delta \theta \frac{w_{i}}{w_{i}-\bar{w}}+((1-\theta) \delta+2(1-\delta))\left(-\frac{2 \Delta}{4-\gamma^{2}} \frac{w_{i}}{\left(4-\gamma^{2}\right)^{-1}\left((2-\gamma) \alpha-2 \Delta w_{i}+\gamma w_{j}\right)}\right)=0 \\
w_{i}=\frac{(2-\gamma) \theta \delta}{2 \Delta(2-\delta)} \alpha+\frac{\theta \delta \gamma}{2 \Delta(2-\delta)} w_{j}+\frac{(2-\delta(1+\theta))}{(2-\delta)} \bar{w},
\end{gathered}
$$

which can be rewritten to keep it comparable to the wage bargain in the no-innovation situation:

$$
w_{i}=\bar{w}+\frac{\theta \delta(2-\gamma)(\alpha-\Delta \bar{w})+\theta \delta \gamma\left(w_{j}-\Delta \bar{w}\right)}{2 \Delta(2-\delta)}
$$

The bargained wage in firm $j$ (conditional that firm $i$ is the innovator) 
reads:

$$
\begin{gathered}
\frac{\partial \Omega}{\partial w_{j}}=\delta \frac{1}{V_{j}}\left(\theta\left(w_{j}-\bar{w}\right)^{\theta-1} x_{j}^{1-\theta}+(1-\theta) x_{j}^{-\theta} \frac{\partial x_{j}}{\partial w_{j}}\left(w_{j}-\bar{w}\right)^{\theta}\right) \\
+(1-\delta) \frac{1}{x_{j}^{2}} 2 x_{j} \frac{\partial x_{j}}{\partial w_{j}}=0 \\
\Leftrightarrow \frac{\partial \Omega}{\partial w_{j}}=\delta\left(\theta \frac{w_{j}}{w_{j}-\bar{w}}+(1-\theta) \frac{\partial x_{j}}{\partial w_{j}} \frac{w_{j}}{x_{j}}\right)+2(1-\delta) \frac{\partial x_{j}}{\partial w_{j}} \frac{w_{j}}{x_{j}}=0 \\
\Leftrightarrow \delta \theta \frac{w_{j}}{w_{j}-\bar{w}}+((1-\theta) \delta+2(1-\delta))\left(-\frac{2}{4-\gamma^{2}} \frac{w_{j}}{\left(4-\gamma^{2}\right)^{-1}\left((2-\gamma) \alpha-2 w_{j}+\gamma \Delta w_{i}\right)}\right)=0 \\
w_{j}-\bar{w}=\frac{\theta \delta\left((2-\gamma) \alpha-2 w_{j}+\gamma \Delta w_{i}\right)}{2(2-\delta-\delta \theta)} \\
\frac{(2-\gamma) \theta \delta}{2(2-\delta)} \alpha+\frac{\theta \delta \gamma \Delta}{2(2-\delta)} w_{i}+\frac{(2-\delta(1+\theta))}{(2-\delta)} \bar{w}
\end{gathered}
$$

which can again be rewritten to yield:

$$
w_{j}=\bar{w}+\frac{\theta \delta(2-\gamma)(\alpha-\bar{w})+\theta \delta \gamma\left(\Delta w_{i}-\bar{w}\right)}{2(2-\delta)}
$$

We can use equations (A.34) and (A.40) to solve for the equilibrium wages in the case of firm $i$ winning the patent race. Rewriting the equilibrium wage system in matrix notation gives:

$$
\underbrace{\left(\begin{array}{cc}
2 \Delta(2-\delta) & -\theta \delta \gamma \\
-\theta \delta \gamma \Delta & 2(2-\delta)
\end{array}\right)}_{\mathbf{A}}\left(\begin{array}{c}
w_{i} \\
w_{j}
\end{array}\right)=\left(\begin{array}{c}
(2-\gamma) \theta \delta \alpha+2 \Delta(2-\delta(1+\theta)) \bar{w} \\
(2-\gamma) \theta \delta \alpha+2(2-\delta(1+\theta)) \bar{w}
\end{array}\right)
$$

The determinant of the coefficient matrix $\mathbf{A}$ is given by:

$$
|\mathbf{A}|=\left(4(2-\delta)^{2}-(\theta \delta \gamma)^{2}\right) \Delta>0 .
$$

With this the equilibrium wages in the right-to-manage case with firm $i$ 
winning the patent race are given by:

$$
\begin{gathered}
w_{i}=\frac{(2-\gamma) \delta \theta(2(2-\delta)+\theta \delta \gamma)}{|\mathbf{A}|} \alpha+\frac{2(2-\gamma(1+\theta))(2(2-\delta) \Delta+\theta \delta \gamma)}{|\mathbf{A}|} \bar{w} \\
w_{j}=\frac{(2-\gamma) \delta \theta \Delta(2(2-\delta)+\theta \delta \gamma)}{|\mathbf{A}|} \alpha+\frac{\Delta 2(2-\gamma(1+\theta))(2(2-\delta)+\theta \delta \gamma \Delta)}{|\mathbf{A}|} \bar{w}
\end{gathered}
$$

Note that since $\Delta<0$, the wage in the innovative firm will be larger than that in the loosing firm. This is due to the fact that the union in the innovative firm is able to capture some of the innovation rent by raising the wage.

Using the expressions for the equilibrium wages, an expression for the following wage differentials (which become important when analysing the equilibrium amount of production and i.e. the equilibrium profit):

$$
\begin{aligned}
& \gamma w_{j}-2 \Delta w_{i}=(\gamma-2) \Delta \frac{(2-\gamma) \delta \theta(2(2-\delta)+\theta \delta \gamma)}{|\mathbf{A}|} \alpha+ \\
& \frac{2(2-\gamma(1+\theta)) \Delta(2(2-\delta)(\gamma-2 \Delta)+\theta \delta \gamma(\Delta \gamma-2))}{|\mathbf{A}|} \bar{w} \\
& \gamma \Delta w_{i}-2 w_{j}=(\gamma-2) \Delta \frac{(2-\gamma) \delta \theta(2(2-\delta)+\theta \delta \gamma)}{|\mathbf{A}|} \alpha+ \\
& \frac{2(2-\gamma(1+\theta)) \Delta(2(2-\delta)(\gamma \Delta-2)+\theta \delta \gamma(\gamma-2 \Delta))}{|\mathbf{A}|} \bar{w}
\end{aligned}
$$

\section{A.2.3 Non-Drastic Innovation}

For the innovation to be non-drastic, equilibrium production of the firm which lost the patent race must be non-zero. Consider firm $i$ has won the race, thus the condition for the innovation to be non-drastic is:

$$
\begin{gathered}
x_{j}=\frac{1}{4-\gamma^{2}}\left((2-\gamma) \alpha-2 \Delta w_{i}+\gamma w_{j}\right)>0 \\
\Leftrightarrow(2-\gamma) \alpha-(2-\gamma) \Delta \frac{(2-\gamma) \delta \theta(2(2-\delta)+\theta \delta \gamma)}{|\mathbf{A}|} \alpha+ \\
\frac{2(2-\gamma(1+\theta)) \Delta(2(2-\delta)(\gamma-2 \Delta)+\theta \delta \gamma(\Delta \gamma-2))}{|\mathbf{A}|} \bar{w}>0
\end{gathered}
$$




\section{A.3 Efficient Bargaining Equilibrium}

\section{A.3.1 Production Decision}

\section{A.3.1.1 No firm has found the Innovation}

$$
\begin{gathered}
\Omega=\left(V_{i}\left(w_{i}, l_{i}\right)\right)^{\delta}\left(\left(p_{i}\left(x_{i}, x_{j}\right)-w_{i}\right) l_{i}\right)^{(1-\delta)} \\
\Leftrightarrow \log \Omega=\delta \log V_{i}\left(w_{i}, l_{i}\right)+(1-\delta) \log \left(p_{i}\left(x_{i}, x_{j}\right)-w_{i}\right)+(1-\delta) \log l_{i}
\end{gathered}
$$

Employment and thus production is in the efficient bargaining case determined via the bargain between the firm and the union given all other endogenous variables.

$$
\begin{gathered}
\frac{\partial \log \Omega}{\partial l_{i}}=\delta V_{i}^{-1}(1-\theta) \frac{V_{i}}{l_{i}}+(1-\delta)\left(p_{i}\left(x_{i}, x_{j}\right)-w_{i}\right)^{-1}(-1)+(1-\delta) l_{i}^{-1}=0 \\
\Leftrightarrow \delta(1-\theta) l_{i}^{-1}+(1-\delta) l_{i}^{-1}=(1-\delta)\left(p_{i}\left(x_{i}, x_{j}\right)-w_{i}\right)^{-1} \\
\Leftrightarrow l_{i} \frac{1}{1-\delta \theta}=\frac{1}{1-\delta}\left(p_{i}\left(x_{i}, x_{j}\right)-w_{i}\right) \\
\Leftrightarrow x_{i} \frac{1-\delta}{1-\delta \theta}=\alpha-x_{i}-\gamma x_{j}-w_{i} \\
\Leftrightarrow x_{i}\left(1+\frac{1-\delta}{1-\delta \theta}\right)=\alpha-\gamma x_{j}-w_{i}
\end{gathered}
$$

which gives the reaction curve for firm $i$ given no innovation has been found:

$$
x_{i}=\chi_{1}^{-1}\left(\alpha-\gamma x_{j}-w_{i}\right),
$$

with $1<\chi_{1}:=1+\frac{1-\delta}{1-\delta \theta}<2$.

Note the similarity to the reaction curve in the right-to-manage case.

Equation (A.48) implicitly constitutes a system of two equations which can be solved for the amount of production in the two firms. The two reaction curves in matrix notation now read:

$$
\left(\begin{array}{cc}
\chi_{1} & \gamma \\
\gamma & \chi_{1}
\end{array}\right)\left(\begin{array}{l}
x_{i} \\
x_{j}
\end{array}\right)=\left(\begin{array}{c}
\alpha-w_{i} \\
\alpha-w_{j}
\end{array}\right)
$$

The solution of the system is eventually:

$$
\begin{aligned}
x_{i} & =\frac{1}{\chi_{1}^{2}-\gamma^{2}}\left(\left(\chi_{1}-\gamma\right) \alpha-\chi_{1} w_{i}+\gamma w_{j}\right) \\
x_{j} & =\frac{1}{\chi_{1}^{2}-\gamma^{2}}\left(\left(\chi_{1}-\gamma\right) \alpha-\chi_{1} w_{j}+\gamma w_{i}\right) .
\end{aligned}
$$


A.3.1.2 Firm $i$ has found the Innovation In this case the production function of firm $i$ changes to $x_{i} \Delta=l_{i}$.

$$
\begin{gathered}
\Omega=\left(V_{i}\left(w_{i}, l_{i}\right)\right)^{\delta}\left(\left(p_{i}\left(x_{i}, x_{j}\right) \Delta^{-1}-w_{i}\right) l_{i}\right)^{(1-\delta)} \\
\Leftrightarrow \log \Omega=\delta \log V_{i}\left(w_{i}, l_{i}\right)+(1-\delta) \log \left(p_{i}\left(\Delta^{-1} l_{i}, x_{j}\right) \Delta^{-1}-w_{i}\right)+(1-\delta) \log l_{i}
\end{gathered}
$$

Employment and thus production is in the efficient bargaining case determined via the bargain between the firm and the union given all other endogenous variables, especially the wage since firm and union bargain simultaneously.

$$
\begin{gathered}
\frac{\partial \log \Omega}{\partial l_{i}}=\delta V_{i}^{-1}(1-\theta) \frac{V_{i}}{l_{i}}+(1-\delta)\left(p_{i}\left(\Delta^{-1} l_{i}, x_{j}\right) \Delta^{-1}-w_{i}\right)^{-1} \Delta^{-1}\left(-\Delta^{-1}\right)+(1-\delta) l_{i}^{-1}=0 \\
\Leftrightarrow \delta(1-\theta) l_{i}^{-1}+(1-\delta) l_{i}^{-1}=(1-\delta)\left(p_{i}\left(\Delta l_{i}, x_{j}\right) \Delta^{-1}-w_{i}\right)^{-1} \Delta^{-1} \Delta^{-1} \\
\Leftrightarrow(1-\delta \theta) l_{i}^{-1}=(1-\delta) \Delta^{-1}\left(p_{i}\left(\Delta l_{i}, x_{j}\right)-\Delta w_{i}\right)^{-1} \\
\Leftrightarrow \frac{l_{i}}{\Delta} \frac{1}{1-\delta \theta}=\frac{1}{1-\delta}\left(p_{i}\left(x_{i}, x_{j}\right)-\Delta w_{i}\right) \\
\Leftrightarrow x_{i} \frac{1-\delta}{1-\delta \theta}=\alpha-x_{i}-\gamma x_{j}-\Delta w_{i} \\
\Leftrightarrow x_{i}\left(1+\frac{1-\delta}{1-\delta \theta}\right)=\alpha-\gamma x_{j}-\Delta w_{i} \\
\Leftrightarrow x_{i} \chi_{1}=\alpha-\gamma x_{j}-\Delta w_{i},
\end{gathered}
$$

which gives the reaction curve for firm $i$ when having won the patent race:

$$
x_{i}=\chi_{1}^{-1}\left(\alpha-\gamma x_{j}-\Delta w_{i}\right)
$$

Since the production situation of firm $j$ does not change compared to the previous paragraph, we can again solve the amount of production in firm $i$ and $j$ using the following system:

$$
\left(\begin{array}{cc}
\chi_{1} & \gamma \\
\gamma & \chi_{1}
\end{array}\right)\left(\begin{array}{l}
x_{i} \\
x_{j}
\end{array}\right)=\left(\begin{array}{c}
\alpha-\Delta w_{i} \\
\alpha-w_{j}
\end{array}\right)
$$

whose solution is;

$$
\begin{aligned}
x_{i} & =\frac{1}{\chi_{1}^{2}-\gamma^{2}}\left(\left(\chi_{1}-\gamma\right) \alpha-\chi_{1} \Delta w_{i}+\gamma w_{j}\right) \\
x_{j} & =\frac{1}{\chi_{1}^{2}-\gamma^{2}}\left(\left(\chi_{1}-\gamma\right) \alpha-\chi_{1} w_{j}+\gamma \Delta w_{i}\right) .
\end{aligned}
$$




\section{A.3.2 Wage Bargaining}

A.3.2.1 No firm has found the Innovation The firm and the union bargain simultaneously the wage and employment. Thus, both partners take the amount of production (i.e. employment) as being fixed during the bargain. Using the same Nash product as in the previous section, we can derive the first order condition which must hold for the bargained wage:

$$
\begin{aligned}
\frac{\partial \log \Omega}{\partial w_{i}}= & \delta V_{i}^{-1} \theta \frac{V_{i}}{\left(w_{i}-\bar{w}\right)}+(1-\delta)\left(p_{i}\left(x_{i}, x_{j}\right)-w_{i}\right)^{-1}(-1)=0 \\
& \Leftrightarrow \delta \theta\left(w_{i}-\bar{w}\right)^{-1}=(1-\delta)\left(p_{i}\left(x_{i}, x_{j}\right)-w_{i}\right)^{-1} \\
& \Leftrightarrow\left(w_{i}-\bar{w}\right) \frac{1-\delta}{\delta \theta}=\left(p_{i}\left(x_{i}, x_{j}\right)-w_{i}\right) \\
& \Leftrightarrow w_{i}\left(\frac{1-\delta}{\delta \theta}\right)=\left(p_{i}\left(x_{i}, x_{j}\right)-w_{i}\right)+\frac{1-\delta}{\delta \theta} \bar{w} \\
\Leftrightarrow & w_{i}(1-\delta)=\delta \theta\left(p_{i}\left(x_{i}, x_{j}\right)-w_{i}\right)+(1-\delta) \bar{w}
\end{aligned}
$$

Using the endogenous demand equation and the expressions for the Nash equilibrium amounts of production bargained in both firms, yields:

$$
\begin{gathered}
p_{i}-w_{i}=\alpha-x_{i}-\gamma x_{j}-w_{i} \\
\Leftrightarrow \alpha-\frac{1}{\chi_{1}^{2}-\gamma^{2}}\left(\left(\chi_{1}-\gamma\right) \alpha-\chi_{1} w_{i}+\gamma w_{j}+\gamma\left(\chi_{1}-\gamma\right) \alpha-\gamma \chi_{1} w_{j}+\gamma^{2} w_{i}\right)-w_{i} \\
\Leftrightarrow \frac{1}{\chi_{1}^{2}-\gamma^{2}}\left(\chi_{1}^{2} \alpha-\gamma^{2} \alpha-\left(\chi_{1}-\gamma\right)(1+\gamma) \alpha+\left(\chi_{1}-\gamma^{2}\right) w_{i}-\left(1-\chi_{1}\right) \gamma w_{j}-\chi_{1}^{2} w_{i}+\gamma^{2} w_{i}\right) \\
\Leftrightarrow \frac{1}{\chi_{1}^{2}-\gamma^{2}}\left(\left(\chi_{1}^{2}-\gamma^{2}-\chi_{1}-\chi_{1} \gamma+\gamma+\gamma^{2}\right) \alpha+\left(\chi_{1}-\gamma^{2}-\chi_{1}^{2}+\gamma^{2}\right) w_{i}+\left(\chi_{1}-1\right) \gamma w_{j}\right) \\
\Leftrightarrow \frac{\chi_{1}-1}{\chi_{1}^{2}-\gamma^{2}}\left(\left(\chi_{1}-\gamma\right) \alpha-\chi_{1} w_{i}+\gamma w_{j}\right) \\
\Leftrightarrow\left(\chi_{1}-1\right) x_{i} \Leftrightarrow \frac{1-\delta}{1-\delta \theta} x_{i}
\end{gathered}
$$

Plugging this in gives the (wage) reaction in firm $i$ in the situation in which 
no firm has found the innovation.

$$
\begin{gathered}
w_{i}(1-\delta)=\delta \theta \frac{1-\delta}{1-\delta \theta} x_{i}+(1-\delta) \bar{w} \\
\Leftrightarrow w_{i}=\frac{\delta \theta}{1-\delta \theta} \frac{1}{\chi_{1}^{2}-\gamma^{2}}\left(\left(\chi_{1}-\gamma\right) \alpha-\chi_{1} w_{i}+\gamma w_{j}\right)+\bar{w} \\
\Leftrightarrow w_{i}\left(1+\frac{\delta \theta}{1-\delta \theta} \frac{\chi_{1}}{\chi_{1}^{2}-\gamma^{2}}\right)=\frac{\delta \theta}{1-\delta \theta} \frac{1}{\chi_{1}^{2}-\gamma^{2}}\left(\left(\chi_{1}-\gamma\right) \alpha+\gamma w_{j}\right)+\bar{w} \\
\Leftrightarrow w_{i}\left(1+\frac{\delta \theta}{1-\delta \theta} \frac{\chi_{1}}{\chi_{1}^{2}-\gamma^{2}}\right)=\frac{\delta \theta}{1-\delta \theta} \frac{1}{\chi_{1}^{2}-\gamma^{2}}\left(\left(\chi_{1}-\gamma\right) \alpha+\gamma w_{j}\right) \\
\Leftrightarrow w_{i}=\bar{w}+\frac{\delta \theta}{1+\frac{\delta \theta}{1-\delta \theta} \frac{1}{\chi_{1}^{2}-\gamma^{2}}}\left(1+\frac{\chi_{1}}{1-\delta \theta} \frac{\chi_{1}}{\chi_{1}^{2}-\gamma^{2}}-\frac{\delta \theta}{1-\delta \theta} \frac{\chi_{1}}{\chi_{1}^{2}-\gamma^{2}}\right) \\
\left.\left.\Leftrightarrow w_{i}=\bar{w}+\frac{\delta \theta\left(\chi_{1}-\gamma\right)(\alpha-\bar{w})+\delta \theta \gamma\left(w_{j}-\bar{w}\right)}{\left(\chi_{1}^{2}-\gamma^{2}\right)(1-\delta \theta)+\chi_{1} \delta \theta} . \bar{w}\right)+\delta \theta \gamma\left(w_{j}-\bar{w}\right)\right)
\end{gathered}
$$

As long as no firm has found the innovation, we have a symmetric equilibrium in which the bargained wage in both firms in an equilibrium is identical. This equilibrium wage is given by:

$$
w=w_{i}=w_{j}=\bar{w}+\frac{\delta \theta\left(\chi_{1}-\gamma\right)(\alpha-\bar{w})}{\left(\chi_{1}^{2}-\gamma^{2}\right)(1-\delta \theta)+\delta \theta\left(\chi_{1}-\gamma\right)}
$$

\section{A.3.2.2 Firm $i$ has found the Innovation}

$$
\begin{gathered}
\frac{\partial \log \Omega}{\partial w_{i}}=\delta V_{i}^{-1} \theta \frac{V_{i}}{\left(w_{i}-\bar{w}\right)}+(1-\delta)\left(p_{i}\left(x_{i}, x_{j}\right)-\Delta w_{i}\right)^{-1}(-\Delta)=0 \\
\Leftrightarrow \delta \theta\left(w_{i}-\bar{w}\right)^{-1}=(1-\delta)\left(p_{i}\left(x_{i}, x_{j}\right)-\Delta w_{i}\right)^{-1} \Delta \\
\Leftrightarrow \Delta w_{i}=\frac{\delta \theta}{1-\delta}\left(p_{i}\left(x_{i}, x_{j}\right)-\Delta w_{i}\right)+\Delta \bar{w}
\end{gathered}
$$

Again it holds that $p_{i}\left(x_{i}, x_{j}\right)-\Delta w_{i}=\left(\chi_{1}-1\right) x_{i}=\frac{1-\delta}{1-\delta \theta} x_{i}$. Plugging this in and using the expression for equilibrium output (A.54) yields the following 
wage reaction function for firm $i$ :

$$
\begin{gathered}
\Delta w_{i}=\frac{\delta \theta}{1-\delta \theta} \frac{1}{\chi_{1}^{2}-\gamma^{2}}\left(\left(\chi_{1}-\gamma\right) \alpha-\chi_{1} \Delta w_{i}+\gamma w_{j}\right)+\Delta \bar{w} \\
\Leftrightarrow \Delta w_{i}\left(1+\frac{\delta \theta}{1-\delta \theta} \frac{\chi_{1}}{\chi_{1}^{2}-\gamma^{2}}\right)=\frac{\delta \theta}{1-\delta \theta} \frac{1}{\chi_{1}^{2}-\gamma^{2}}\left(\left(\chi_{1}-\gamma\right) \alpha+\gamma w_{j}\right)+\Delta \bar{w} \\
\Leftrightarrow \Delta w_{i}\left(1+\frac{\delta \theta}{1-\delta \theta} \frac{\chi_{1}}{\chi_{1}^{2}-\gamma^{2}}\right)=\frac{\delta \theta}{1-\delta \theta} \frac{1}{\chi_{1}^{2}-\gamma^{2}}\left(\left(\chi_{1}-\gamma\right) \alpha+\gamma w_{j}\right) \\
\Leftrightarrow \Delta w_{i}=\Delta \bar{w}+\frac{\frac{\delta \theta}{1-\delta \theta} \frac{1}{\chi_{1}^{2}-\gamma^{2}}}{1+\frac{\delta \theta}{1-\delta \theta} \frac{\chi_{1}}{\chi_{1}^{2}-\gamma^{2}}}\left(\left(\chi_{1}-\gamma\right)(\alpha-\Delta \theta \bar{w})+\gamma\left(w_{j}-\Delta \bar{w}\right)\right) \\
\left.\Leftrightarrow \Delta w_{i}=\Delta \bar{w}+\frac{\delta \theta\left(\chi_{1}-\gamma\right)(\alpha-\Delta \bar{w})+\delta \theta \gamma\left(w_{j}-\Delta \bar{w}\right)}{\chi_{1}^{2}-\gamma^{2}}-\frac{\delta \theta}{1-\delta \theta}\right) \\
\left(\chi_{1}^{2}-\gamma^{2}\right)(1-\delta \theta)+\chi_{1} \delta \theta
\end{gathered}
$$

The output reaction curve of firm $j$ does not change as was derived in the previous section. However, equilibrium output does change in case of firm $i$ being innovative. This spills-over to the wage bargain. Hence, the reaction function in factor prices does change.

$$
\begin{gathered}
\frac{\partial \log \Omega}{\partial w_{j}}=\delta V_{j}^{-1} \theta \frac{V_{j}}{\left(w_{j}-\bar{w}\right)}+(1-\delta)\left(p_{j}\left(x_{i}, x_{j}\right)-w_{j}\right)^{-1}(-1)=0 \\
\Leftrightarrow \delta \theta\left(w_{j}-\bar{w}\right)^{-1}=(1-\delta)\left(p_{j}\left(x_{i}, x_{j}\right)-w_{j}\right)^{-1} \\
\Leftrightarrow w_{j}=\frac{\delta \theta}{1-\delta}\left(p_{j}\left(x_{i}, x_{j}\right)-w_{j}\right)+\bar{w} .
\end{gathered}
$$

In an equilibrium output situation the following holds again $\left(p_{j}\left(x_{i}, x_{j}\right)-\right.$ 
$\left.w_{j}\right)=\left(\chi_{1}-1\right) x_{j}=\frac{1-\delta}{1-\delta \theta} x_{j}$. Using the equilibrium output (A.55) yields:

$$
\begin{gathered}
w_{j}=\frac{\delta \theta}{1-\delta \theta} \frac{1}{\chi_{1}^{2}-\gamma^{2}}\left(\left(\chi_{1}-\gamma\right) \alpha-\chi_{1} w_{j}+\gamma \Delta w_{i}\right)+\bar{w} \\
\Leftrightarrow w_{j}\left(1+\frac{\delta \theta}{1-\delta \theta} \frac{\chi_{1}}{\chi_{1}^{2}-\gamma^{2}}\right)=\frac{\delta \theta}{1-\delta \theta} \frac{1}{\chi_{1}^{2}-\gamma^{2}}\left(\left(\chi_{1}-\gamma\right) \alpha+\gamma \Delta w_{i}\right)+\bar{w} \\
\Leftrightarrow w_{j}\left(1+\frac{\delta \theta}{1-\delta \theta} \frac{\chi_{1}}{\chi_{1}^{2}-\gamma^{2}}\right)=\frac{\delta \theta}{1-\delta \theta} \frac{1}{\chi_{1}^{2}-\gamma^{2}}\left(\left(\chi_{1}-\gamma\right) \alpha+\gamma \Delta w_{i}\right) \\
+\bar{w}\left(1+\left(1+\frac{\delta \theta}{1-\delta \theta} \frac{\chi_{1}}{\chi_{1}^{2}-\gamma^{2}}\right)-\left(1+\frac{\delta \theta}{1-\delta \theta} \frac{\chi_{1}}{\chi_{1}^{2}-\gamma^{2}}\right)\right) \\
\Leftrightarrow w_{j}=\bar{w}+\frac{\frac{\delta \theta}{1-\delta \theta} \frac{1}{\chi_{1}^{2}-\gamma^{2}}}{1+\frac{\delta \theta}{1-\delta \theta} \frac{\chi_{1}}{\chi_{1}^{2}-\gamma^{2}}}\left(\left(\chi_{1}-\gamma\right)(\alpha-\bar{w})+\gamma\left(\Delta w_{i}-\bar{w}\right)\right) \\
\Leftrightarrow w_{j}=\bar{w}+\frac{\delta \theta\left(\chi_{1}-\gamma\right)(\alpha-\bar{w})+\delta \theta \gamma\left(\Delta w_{i}-\bar{w}\right)}{\left(\chi_{1}^{2}-\gamma^{2}\right)(1-\delta \theta)+\chi_{1} \delta \theta}
\end{gathered}
$$

The two factor market reaction functions constitute a system of equations which determines the Nash equilibrium. This system reads in matrix notation:

$$
\underbrace{\left(\begin{array}{cc}
\Delta \chi_{2} & -\delta \theta \gamma \\
-\delta \theta \gamma \Delta & \chi_{2}
\end{array}\right)}_{\mathbf{B}}\left(\begin{array}{c}
w_{i} \\
w_{j}
\end{array}\right)=\left(\begin{array}{c}
\left(\chi_{1}-\gamma\right) \delta \theta \alpha+\left(\chi_{1}^{2}-\gamma^{2}\right)(1-\delta \theta) \Delta \bar{w} \\
\left(\chi_{1}-\gamma\right) \delta \theta \alpha+\left(\chi_{1}^{2}-\gamma^{2}\right)(1-\delta \theta) \bar{w}
\end{array}\right)
$$

where $\chi_{2}:=\left(\chi_{1}^{2}-\gamma^{2}\right)(1-\delta \theta)+\chi_{1} \delta \theta$. The determinant of the matrix $\mathbf{B}$ is given by:

$$
|\mathbf{B}|=\left(\chi_{2}^{2}-(\delta \theta \gamma)^{2}\right) \Delta>0
$$

Thus the equilibrium wage in firm $i$ and $j$ in a situation in which firm $i$ has found the innovation is given by:

$$
\begin{gathered}
w_{i}=\frac{\left(\chi_{1}-\gamma\right) \delta \theta\left(\chi_{2}+\delta \theta \gamma\right)}{|\mathbf{B}|} \alpha+\frac{\left(\chi_{1}^{2}-\gamma^{2}\right)(1-\delta \theta)\left(\chi_{2} \Delta+\delta \theta \gamma\right)}{|\mathbf{B}|} \bar{w} \\
w_{j}=\frac{\Delta\left(\chi_{1}-\gamma\right) \delta \theta\left(\chi_{2}+\delta \theta \gamma\right)}{|\mathbf{B}|} \alpha+\frac{\Delta\left(\chi_{1}^{2}-\gamma^{2}\right)(1-\delta \theta)\left(\chi_{2}+\delta \theta \gamma \Delta\right)}{|\mathbf{B}|} \bar{w}
\end{gathered}
$$


Not for further reference that in an equilibrium situation the following holds:

$$
\begin{array}{r}
\gamma w_{j}-\chi_{1} \Delta w_{i}=\frac{\Delta\left(\chi_{1}-\gamma\right) \delta \theta\left(\chi_{2}+\delta \theta \gamma\right)}{|\mathbf{B}|}\left(\gamma-\chi_{1}\right) \alpha \\
+\frac{\Delta\left(\chi_{1}^{2}-\gamma^{2}\right)(1-\delta \theta)}{|\mathbf{B}|}\left(\chi_{2}\left(\gamma-\Delta \chi_{1}\right)+\delta \theta \gamma\left(\gamma \Delta-\chi_{1}\right)\right) \bar{w}
\end{array}
$$

and

$$
\begin{array}{r}
\gamma \Delta w_{i}-\chi_{1} w_{j}=\frac{\Delta\left(\chi_{1}-\gamma\right) \delta \theta\left(\chi_{2}+\delta \theta \gamma\right)}{|\mathbf{B}|}\left(\gamma-\chi_{1}\right) \alpha \\
+\frac{\Delta\left(\chi_{1}^{2}-\gamma^{2}\right)(1-\delta \theta)}{|\mathbf{B}|}\left(\chi_{2}\left(\gamma \Delta-\chi_{1}\right)+\delta \theta \gamma\left(\gamma-\chi_{1} \Delta\right)\right) \bar{w} .
\end{array}
$$

\section{A.3.3 Non-Drastic Innovation}

As in the situation with right-to-manage, a non-drastic innovations implies that the output of the loosing firm remains positive. Hence, the condition for a non-drastic innovation reads:

$$
\begin{gathered}
x_{j}=\frac{1}{\chi_{1}^{2}-\gamma^{2}}\left(\left(\chi_{1}-\gamma\right) \alpha+\gamma \Delta w_{i}-\chi_{1} w_{j}\right)>0 \\
\Leftrightarrow\left(\chi_{1}-\gamma\right) \alpha-\left(\chi_{1}-\gamma\right) \frac{\Delta\left(\chi_{1}-\gamma\right) \delta \theta\left(\chi_{2}+\delta \theta \gamma\right)}{|\mathbf{B}|} \alpha \\
+\frac{\Delta\left(\chi_{1}^{2}-\gamma^{2}\right)(1-\delta \theta)}{|\mathbf{B}|}\left(\chi_{2}\left(\gamma \Delta-\chi_{1}\right)+\delta \theta \gamma\left(\gamma-\chi_{1} \Delta\right)\right) \bar{w}>0
\end{gathered}
$$

